\title{
PESCADORES DEL DESIERTO: OCUPACIÓN Y SUBSISTENCIA EN LA MARGEN OESTE DEL RÍO DESAGUADERO (CENTRO OESTE ARGENTINO) ENTRE LOS CA. 1200 Y 400 AÑNS AP
}

\author{
FISHERMEN OF THE DESERT: OCCUPATION AND SUBSISTENCE \\ ON THE WEST SIDE OF THE DESAGUADERO RIVER (WEST-CENTRAL \\ ARGENTINA) BETWEEN CA. 1200 AND 400 BP \\ Horacio Chiavazza ${ }^{1,2}$, Cristina Prieto-Olavarría ${ }^{1,2,3}$, Fernando Hernández $z^{2}$, \\ Lorena Puebla ${ }^{1,2}$, Marcos Quiroga ${ }^{1,2}$ y Jorge Anzorena ${ }^{2}$
}

\begin{abstract}
Se presentan resultados del estudio arqueológico del sitio PA68, en el sector de laguna El Quebrachito, ubicado sobre una duna luneta aledaña a un antiguo humedal del Río Desaguadero (Gran Llanura de la Travesía, Centro Oeste Argentino). Con base en los resultados de las dataciones radiocarbónicas y del análisis de los materiales cerámico, arqueofaunístico y lítico, se postula que entre los ca. 1200 y 800 años AP, durante la Anomalía Climática Medieval, las poblaciones humanas intensificaron la ocupación del área y del sitio en particular. También se registran ocupaciones, dentro de un patrón de movilidad logística, en torno a los ca. 400 años AP durante la Pequeña Edad de Hielo. Por tratarse de contextos depositados sobre una duna, presentan fuertes modificaciones, las que no obstaculizan la interpretación del proceso de uso de ambientes ribereños con ocupaciones vinculadas a modos de subsistencia con énfasis en la pesca y tecnologías que aprovecharon recursos minerales del norte de Mendoza y de otras fuentes ubicadas al este del área de estudio.
\end{abstract}

Palabras claves: Centro Oeste Argentino, Río Desaguadero, humedal, Anomalía Climática Medieval, asentamiento, subsistencia.

This article presents the results of the archaeological study of the PA68 site in the El Quebrachito lagoon, located on a lunette sand dune next to an old wetland of the Desaguadero River (Gran Llanura de la Travesía, west-central Argentina). Based on the results of radiocarbon dating and of ceramic, archaeofaunistic, and lithic material analyses, it is postulated that between ca. 1200 and 800 years BP, during the Medieval Climate Optimum, populations intensified the occupation of the area and of this site in particular. Occupations, within a logistic mobility pattern, around ca. 400 years BP during the Little Ice Age are also recorded. Although strong alterations can be observed in these remains, as they are deposited in the dunes, these do not hinder the interpretation of the process of use of riverside environments with occupations linked to subsistence modes, focused on fishing and technologies, which took advantage of mineral resources in the north of Mendoza, as well as others to the east of the study area.

Key words: West-central Argentina, Desaguadero River, wetland, Medieval Climatic Anomaly, settlement, subsistence.

Las tierras secas ocupan el $41 \%$ de la superficie terrestre (Banaag 2006), tipificadas por estar por debajo de los $250 \mathrm{~mm}$ de precipitaciones al año (Aronson 2008). Históricamente, las densidades de población en ellas son bajas (Veth 2005) y gran parte de estas zonas presentan discontinuidades de las ocupaciones humanas, con áreas de concentración y otras despobladas, aunque no necesariamente deshabitadas (Berenguer y Pimentel 2017).

Desde hace dos décadas se plantea la relevancia que poseen las tierras bajas y áridas para el análisis de los procesos de poblamiento del territorio central de Argentina. Recientemente se sintetizaron los antecedentes y orientaciones en base al estudio

1 Universidad Nacional de Cuyo, Facultad de Filosofía y Letras, Instituto de Arqueología y Etnología, Laboratorio de Arqueología Histórica y Etnohistoria, Mendoza, Argentina. hchiavazza@gmail.com; cprieto@mendoza-conicet.gob.ar; lorenaivanapuebla@gmail.com; marcos.graco@gmail.com

2 Centro de Investigaciones Ruinas de San Francisco, Área Fundacional, Municipalidad de Mendoza, Mendoza, Argentina. josefernah@gmail.com, jorgeanzorenaunc@gmail.com

3 Instituto Argentino de Nivología, Glaciología y Ciencias Ambientales, Consejo Nacional de Investigaciones Científicas y Técnicas, Mendoza, Argentina. 
interdisciplinario del tramo de la Diagonal Árida Sudamericana, coincidente con las Travesías del Centro de Argentina, lo que ha generado una visión de conjunto que permite nuevas interpretaciones arqueológicas desde el punto de vista biogeográfico (Heider et al. 2019). En comparación con el análisis regional mencionado, en este caso contribuimos a la problemática que analiza las relaciones entre las ocupaciones humanas y el ambiente desde la escala de sitio. A tal fin, presentamos el estudio del registro arqueológico del sitio PA68 ubicado en las inmediaciones de un antiguo humedal asociado a la laguna de El Quebrachito (denominada Gualen en la cartografía del siglo XVIII), a dos kilómetros de la margen oeste del actual curso del Río Desaguadero, límite oriental de la árida Planicie NE de Mendoza, Centro Oeste Argentino (COA) (Figura 1). Este sitio presenta una extensa dispersión de materiales con algunas concentraciones relacionadas con la topografía propia de una duna luneta que -con depresiones, laderas y cumbre- divide dos bajos de deflación donde habrían funcionado lagunas, actualmente secas.
Los estudios pioneros indicaron que el Río Desaguadero en Mendoza fue el límite de las culturas arqueológicas Agrelo y Viluco, respecto de aquellas que se desarrollaron hacia el este y que fueron vinculadas al grupo étnico Huarpe Comechingón de San Luis (Canals Frau 1944; Lagiglia 1978). Las investigaciones arqueológicas eran casi inexistentes en este curso de agua, hasta que comenzamos a realizar prospecciones sistemáticas hace más de 10 años (Chiavazza y Prieto 2008, 2015). Los trabajos de campo realizados entre el sector de San Miguel y el Arroyo Jarilla, ubicados al norte y al sur de la cuenca del Río Desaguadero respectivamente, mostraron que los sitios PA68 y Paso de Los Blancos (PA57) eran los de mayor tamaño y con mayor densidad de materiales del área (Chiavazza y Prieto 2008, 2015). Estos estudios se abordaron considerando que el borde del río y los humedales asociados fueron ambientes particularmente atractivos para el asentamiento humano (Chiavazza y Prieto 2008, 2015; Chiavazza y Hernández 2015; Chiavazza et al. 2014; Prieto Olavarría et al. 2016), ya que la Planicie NE de Mendoza es una vasta extensión árida en la cual el déficit hídrico es permanente (Hijmans

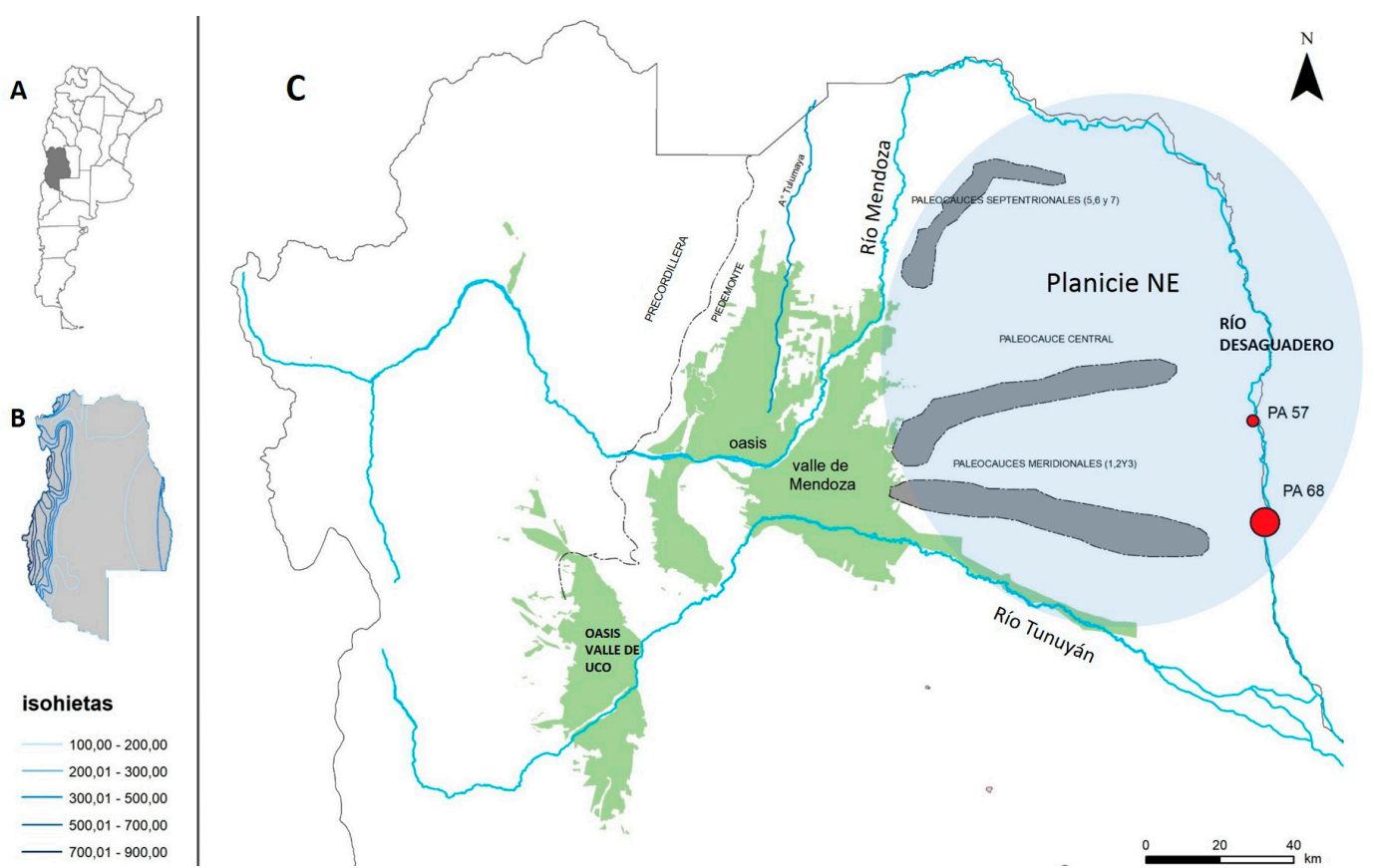

Figura 1. Área de estudio y ubicación relativa del sitio PA68. (A) Argentina y provincia de Mendoza; (B) provincia de Mendoza e isohietas (Norte 2000), unidades en milímetros; (C) ubicación del Río Desaguadero y de los sitios PA68 y PA57 en relación al norte y centro de la provincia de Mendoza, sus respectivos oasis, ríos, y la Planicie NE (área sombreada).

Study area and relative location of the PA68 site. (A) Argentina and Mendoza Province; (B) Mendoza Province and isohyets (Norte 2000), units in millimeters; (C) location of Desaguadero River and PA68 and PA57 sites in relation to the north and center of the Mendoza Province, their respective oases, rivers, and the NE Plain (shaded area). 
et al. 2005; Trabucco y Zomer 2009) (Figura 1) y el agua es un recurso crítico para la organización del patrón de asentamiento humano (Chiavazza 2001). En este sentido, la Gran Llanura de la Travesía -que se extiende en las provincias de Mendoza y San Luis entre el piedemonte y las Sierras Pampeanas (Polanski 1954)- fue tratada recientemente como un espacio ocupado a partir de la existencia de ecorefugios y donde el agua fue el recurso disponible con certidumbre en este marco árido-semiárido, como el caso de la Travesía de San Luis (Heider et al. 2019).

El objetivo de este trabajo es caracterizar las ocupaciones humanas en el sitio PA68, ubicado en un humedal que funcionó en un contexto ambiental fluctuante dentro del desierto de la Planicie NE de Mendoza. Para lograrlo, se integró la información del registro cerámico, lítico y arqueofaunístico, con los fechados obtenidos de carbón vegetal. La identificación y análisis de los aspectos tecnológicos y económicos, en un rango cronológico relativamente acotado, se analizó en el marco de las condiciones ambientales descriptas para la región durante los últimos 2000 años.

\section{Contexto Ambiental y Condiciones Paleoclimáticas}

Casi la mitad del territorio de Mendoza está formado por extensas planicies que integran parte de la Gran Llanura de la Travesía y limitan al oeste con el piedemonte precordillerano y al este con el Río Desaguadero (Rodríguez y Barton 1993). El sector NE de estas planicies (Planicie NE de Mendoza), se caracteriza por extensos y continuos campos de dunas, seccionados por ramblones, superficies de inundación y antiguos cauces que indican disponibilidad hídrica variable en el pasado y dinámicas de encharcamientos estivales (Abraham y Prieto 1981; Chiavazza 2001, 2014). Presenta características de un desierto de arenas, con déficit hídrico anual permanente y un marco vegetacional y faunístico propio de la Provincia Fitogeográfica del Monte (Morello 1959; Roig et al. 2000).

El Río Desaguadero pertenece a la cuenca del Desaguadero-Salado-Chadileuvú-Curacó, que discurre por $1.000 \mathrm{~km}$ a lo largo de una franja árida conocida como Diagonal Árida Sudamericana (Bruniard 1982). El tramo I del río (sensu Bereciartua 2009) atraviesa la Gran Llanura de la Travesía (Heider et al. 2019) y de norte a sur presenta una traza continua, con caudal permanente y humedales de diversas dimensiones que fluctúan estacionalmente (Ojeda et al. 2013). Se encuentra bajo influencia del dominio del Océano Pacífico y de los aportes hídricos superficiales y subterráneos que provienen de la región cordillerana, donde la recarga está dominada por lluvias y nevadas invernales (Garreaud et al. 2009), dando así sus máximos caudales a fines de primavera e inicios del verano (diciembre-enero) (Bereciartua 2009). Geográficamente, este curso de agua constituye el límite oriental de la Planicie NE de Mendoza y manifiesta diferencias en sus dos márgenes, las que, si bien corresponden a una continua vegetación del Monte, varían en la densidad y distribución, acrecentando la variabilidad de especies conforme se avanza hacia el este. Este aspecto se relacionaría con las características geomorfológicas particulares del área, también diferenciadas entre oeste y este (Ojeda et al. 2013).

Las condiciones paleoclimáticas del COA se conocen a partir de registros de resolución de grano grueso. El estudio de los registros de polen de turba indica que alrededor de los 3.000 años AP se establecieron las condiciones climáticas modernas, con precipitaciones de lluvia de verano en las tierras bajas y temperaturas más favorables en las tierras altas (Markgraf 1989). La dinámica de los glaciares en el área occidental indica que el episodio más reciente de avance glaciar generalizado durante el Holoceno ocurrió durante la Pequeña Edad de Hielo (PEH) (Villalba 1994), con un avance máximo ocurrido durante el periodo de 1550-1720 y uno posterior datado en ca. 1830 (Espizúa y Pitte 2009). Esto influyó en la disponibilidad de agua de los ríos de la llanura, alimentada por las nevadas estacionales y los glaciares. Se plantea que durante la Anomalía Climática Medieval aumentó el volumen de los sistemas fluviolacustres en un marco más húmedo y cálido en las planicies, mientras que durante al PEH se habría registrado un clima templado semiáridoárido con disminución de sistemas fluviolacustres hacia las llanuras y avances de los glaciares andinos (Cioccale 1999).

Por su parte, el estudio de la dinámica de campos de dunas en la llanura aporta información paleoclimática relevante para el análisis del proceso poblacional de las tierras bajas orientales (Tripaldi y Forman 2007). En el campo de dunas Médanos Grandes (provincia de San Juan), desarrollado inmediatamente al norte de nuestra zona de estudio, se reconoció actividad eólica en ca. 3685-4800 años b2k, con deposición de arena eólica posiblemente 
concurrente hacia los ca. 1920-2220 años b2k y ca. 365-445 años b2k, en coincidencia con la PEH (Tripaldi y Forman 2007). En el área del Río Desaguadero, investigaciones geomorfológicas y fechados de las dunas, también permitieron relacionar actividades de dunas con eventos paleoclimáticos (Ojeda et al. 2012; 2013). En el área dentro de la cual se encuentra el sitio de estudio, se propuso que las dunas luneta se asocian a la deflación desde las costas occidentales de lagunas temporales vinculadas a inundaciones del Río Desaguadero (Ojeda et al. 2013). Las dataciones realizadas sobre restos de conchillas, indican que estas dunas se habrían formado durante el Holoceno Superior y vinculadas a la Anomalía Climática Medieval en un rango dado entre $1210 \pm 50$ y $690 \pm 90$ años AP (Ojeda et al. 2013:121). Posteriormente, durante el deterioro climático de la PEH (ca. 600 a 150 años AP), se habrían desarrollado dunas longitudinales y mantos arenosos debido a los aportes sedimentarios procedentes de la llanura aluvial del Río Desaguadero y a la removilización de arenas de las dunas luneta formadas previamente (Ojeda et al. 2012; Ojeda et al. 2013). El proceso de desecación de las lagunas y la formación de dunas longitudinales se correlacionaría con la PEH (Ojeda et al. 2013).

En una escala más detallada, se han observado dinámicas de transformación importantes en el paisaje al comparar el tamaño de los cuerpos de agua durante ciclos cortos en tiempos recientes, aspecto que se considera crítico para la organización del asentamiento humano en un entorno árido (Ojeda et al. 2013). El

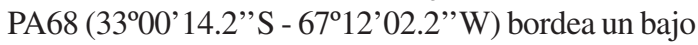
de deflación, que funcionó como laguna, actualmente seca, pero que experimentó reactivaciones intermitentes en tiempos recientes en concordancia con episodios El Niño intensos (verano de 1987-1988) (Ojeda et al. 2013) (Figura 2).

\section{Estudios Arqueológicos e Históricos en el Río Desaguadero}

Desde hace más de una década centramos nuestras investigaciones en el Río Desaguadero con el objetivo de evaluar el patrón de asentamiento y su inserción en la problemática regional, a partir de prospecciones extensivas, excavaciones y análisis de materiales (Chiavazza y Prieto 2008, 2015; Chiavazza y Hernández 2015; Chiavazza et al. 2014; Guardia y Francalancia 2015; López y Chiavazza 2019; Prieto-Olavarría et al. 2016). Estas se sustentaron en la propuesta surgida de los estudios en la Planicie NE, que planteaba que en un ambiente con déficit hídrico permanente los sectores más atractivos para el asentamiento humano eran aquellos con disponibilidad de agua permanente, como lagunas, cauces de ríos actuales (Chiavazza 2001, 2012a, 2012b) y Paleocauces (Septentrionales, Centrales y Meridionales) (Chiavazza 2014). De las investigaciones precedentes, contábamos con información de solo tres sitios en la margen occidental del río y con escasas referencias a los materiales arqueológicos: Las Tunitas, Puesto de las Carretas y Paso El Encón (Rusconi 1962).

Las primeras investigaciones arqueológicas sistemáticas permitieron constatar la relevancia del Río Desaguadero para el asentamiento humano y definirlo como un territorio de borde entre los paisajes áridos de la Planicie NE de Mendoza y el paisaje serrano central de San Luis, ubicado entre 30 y $80 \mathrm{~km}$ al este (Chiavazza y Prieto 2008). El análisis de materias primas reportó el uso de recursos procedentes de Sierras Pampeanas para la industria lítica (cuarcitas), así como también para los antiplásticos usados en gran parte de las pastas cerámicas, lo que permitió volver a pensar en la dinámica de las poblaciones que ocuparon este sector, tanto la movilidad como el intercambio en un área que más que límite cultural, pudo ser atractiva para el asentamiento de grupos provenientes tanto del oeste como del este (Chiavazza 2001; Chiavazza y Prieto 2008; Prieto-Olavarría 2019; Prieto-Olavarría et al. 2016).

Los documentos históricos -que incluyen valiosa información de mapas, como el de José Ximenez de Inguanzo (1789) (Figura 3)- han sido fuente de información para conocer la ocupación del área durante los siglos XVII, XVIII y XIX. La información relevada indica que los bordes y humedales fueron ocupados a partir de una estructura de asentamiento disperso y caracterizado por caseríos asociados a lagunas y cursos de agua unidos por "caminos por donde los naturales" se movilizaban (José Ximenez de Inguanzo 1789, en Chiavazza 2015a:144). Estos caminos se extendieron entre la Laguna de las Quijadas en el extremo norte, hasta el sector de Corocorto al sur (Departamento de La Paz) (Chiavazza 2015a). La documentación muestra, además, que el impacto generado por el proceso de conquista e incorporación de mano de obra nativa al régimen sociopolítico y económico colonial supuso un descenso poblacional y una retracción y desaparición de los asentamientos de los nativos (Chiavazza y Prieto 2015). Hasta el siglo XVIII, se registra un patrón de movilidad ligado a la disponibilidad de agua, lo que se observa en sitios 

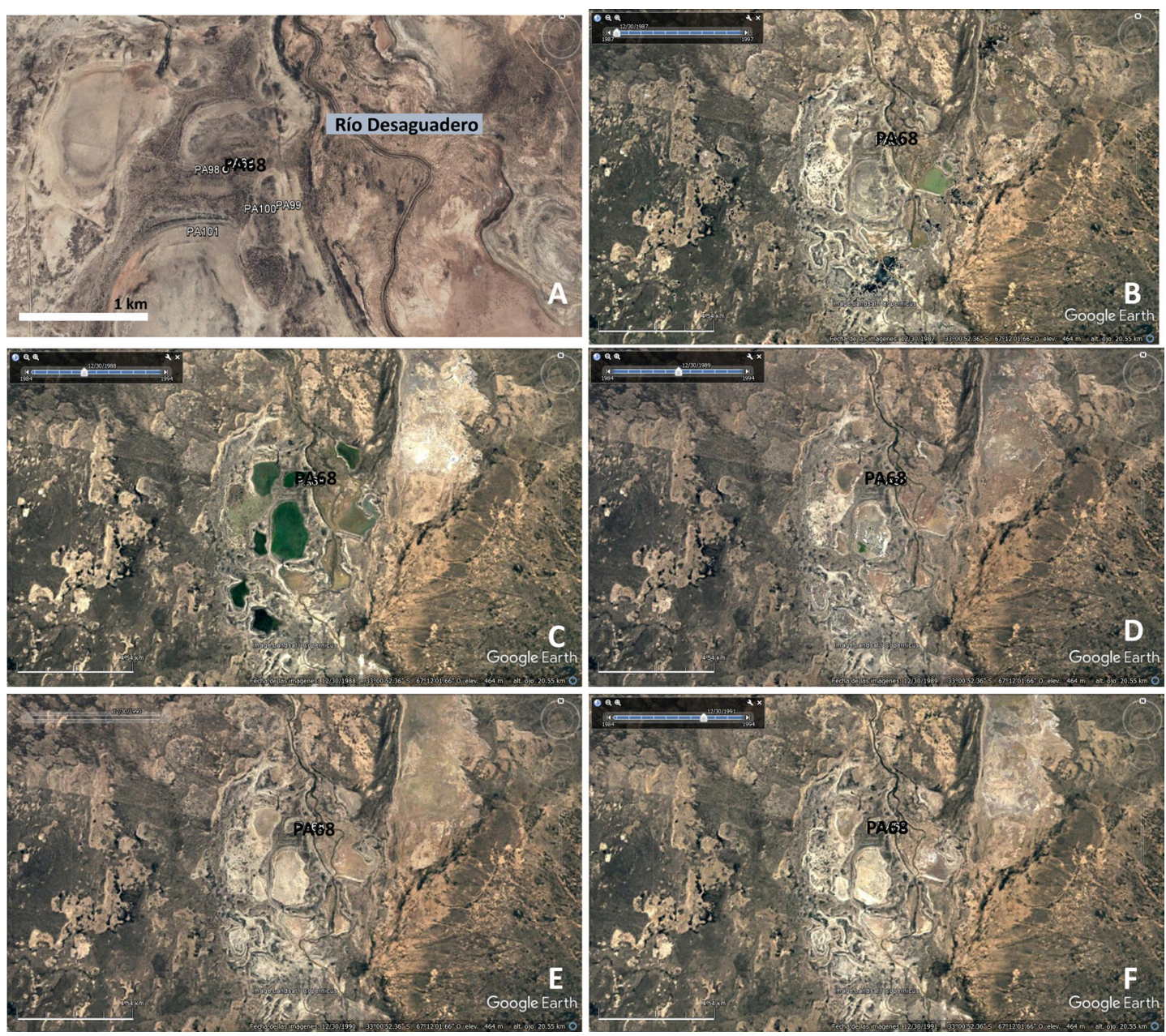

Figura 2. Imágenes satelitales del área del sitio PA68. (A) Imagen reciente de laguna El Quebrachito y ubicación del PA68; (B) imagen del área en diciembre de 1987 (se observa el desarrollo del humedal); C) imagen del área en diciembre de 1988 (se mantienen lagunas); (D) estado del área en diciembre de 1989 (se observa ausencia humedales); (E) imagen del área en diciembre de 1990; (F) imagen del área en diciembre del 1991. La escala de las imágenes B a F es de $4.54 \mathrm{~km}$ y las coordenadas son 3300'52.36' $\mathrm{S}$ 67¹2’01.66’'O. Imágenes tomadas de Google Earth en julio de 2016.

Satellite images of the PA68 site area. (A) Recent image of the El Quebrachito lagoon and PA68 location; (B) image of the area in December 1987 (note the development of the wetland); (C) image of the area in December 1988 (lagoons remain); (D) image of the area in December 1989 (note the absence of wetlands); (E) image of the area in December 1990; $(F)$ image of the area in

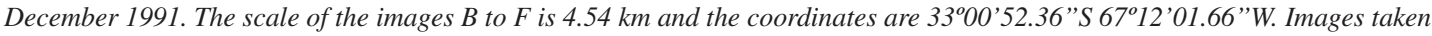
from Google Earth in July 2016.

arqueológicos resultantes de bases residenciales orientadas a la pesca, la recolección y la cacería (Chiavazza y Prieto 2015). Durante este siglo las estrategias de subsistencia cambiaron debido a que las condiciones del humedal variaron, y dieron paso al vaciamiento poblacional -observable en la gran cantidad de puestos abandonados en los alrededores de los complejos lacustres secos- que se produjo en los siglos XIX y XX, debido a la creciente explotación agrícola en el oasis mendocino y al consecuente proceso de desertificación y vaciamiento de lagunas, lo que señala la sensibilidad del asentamiento humano respecto a la disponibilidad de agua (Chiavazza y Prieto 2015).

El primer estudio arqueológico en el Río Desaguadero se desarrolló en el sitio Cruz Blanca (PA57) (Figura 1) (Chiavazza y Prieto 2008), y se propuso que fue ocupado de modo intenso y sostenido entre los ca. 1600 y 400 años AP, bajo un régimen de relativa variabilidad en la disponibilidad hídrica. 


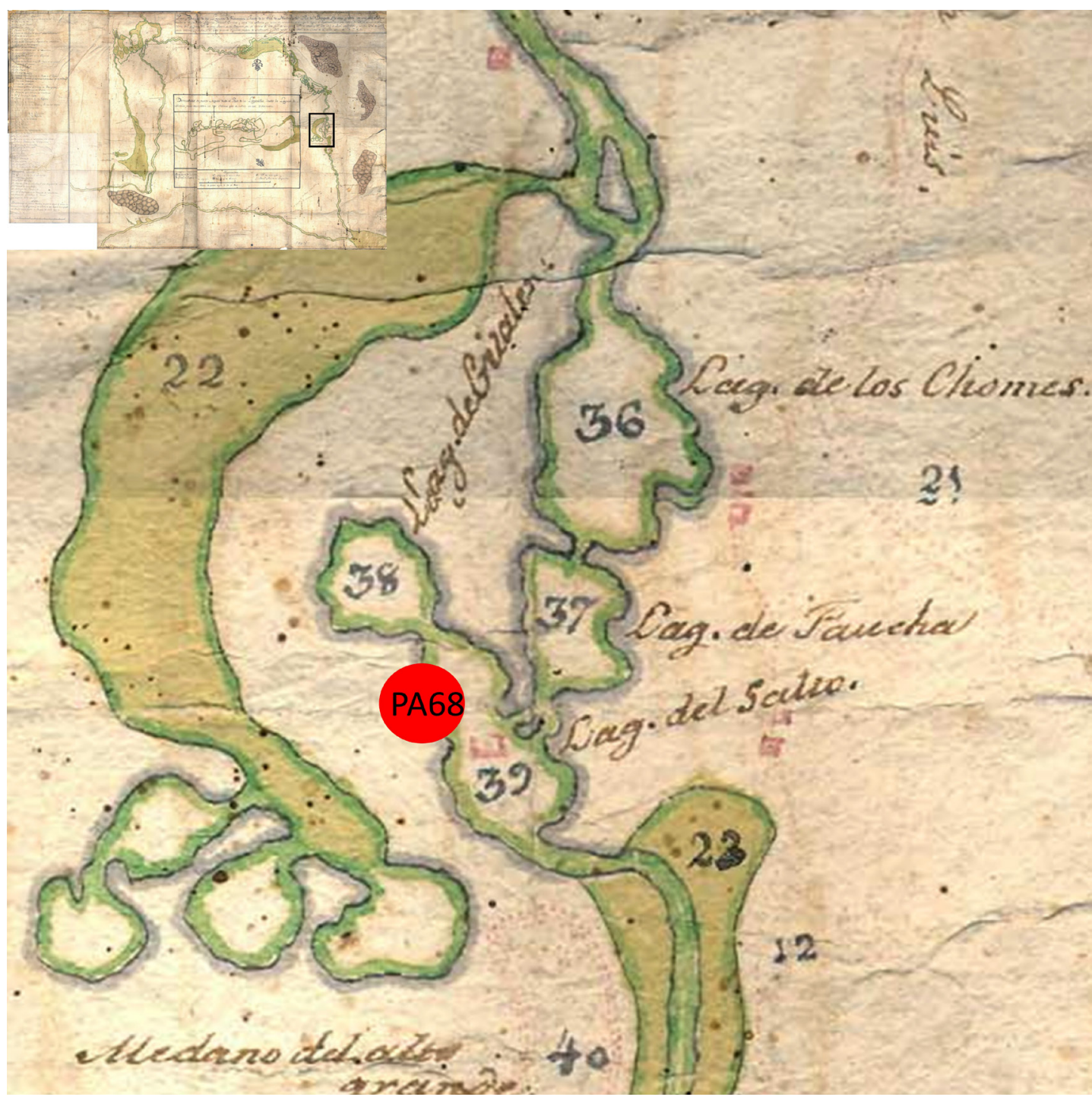

Figura 3. PA68 ubicado en el recuadro ampliado del mapa de Don José Ximenez de Inguanzo (arriba izquierda) que data de 1789 (imagen tomada de Chiavazza 2007:42).

PA68 located in the enlarged box of Don José Ximenez de Inguanzo's map (top leaf corner) dating from 1789 (image taken from Chiavazza 2007:42).

Esta cambió drásticamente hace unos 100 años, cuando comenzaron las roturas de diques naturales que generaron procesos de erosión retrocedente y la disminución, e incluso desaparición, de los humedales del Desaguadero (Chiavazza y Prieto 2008).

Hace algunos años se presentaron los resultados preliminares del trabajo de campo del sitio PA68 (Chiavazza y Hernández 2015; Chiavazza et al. 2014). Por su parte, el análisis cerámico reveló la presencia de diversos estilos tecnológicos, correspondientes a cerámica producida por artesanos pertenecientes a distintas tradiciones alfareras, que incluye fragmentos de vasijas caracterizadas para el periodo Alfarero Medio (cerámica Agrelo y Grupo Gris Marrón, que presentan la mayor variabilidad de estilos tecnológicos) y del Tardío/Colonial (Viluco Inca Mixto) del norte de Mendoza (Prieto-Olavarría et al. 2016). Junto a estos, se encontraron fragmentos elaborados con materias primas provenientes de las Sierras Pampeanas, ubicadas en el norte y este del Río Desaguadero (Prieto-Olavarría 2019). Esta evidencia permitió plantear que la ubicación del sitio en un humedal 
en el límite cultural y corredor poblacional en el eje norte-sur, fueron características que estimularon el asentamiento de poblaciones de diversos orígenes, tanto del norte de Mendoza como del este, durante el lapso comprendido entre los 1200 y 400 años AP (Prieto-Olavarría et al. 2016).

\section{Materiales y Método}

La localidad de lagunas El Quebrachito se prospectó a partir de tres transectas de $2.300 \mathrm{~m}$ de largo y ocho m de ancho cada una, incluyendo formaciones de dunas, bordes y fondos, y bajos de deflación, y se detectaron cinco puntos arqueológicos, todos sobre dunas (PA68, PA98, PA99, PA100, PA101). Los trabajos se centraron en el PA68, que posee $44.000 \mathrm{~m}^{2}$ de área. En base al relevamiento de la superficie se marcaron 251 mapeos (incluyen hallazgos aislados y conjuntos de materiales que no superaban $1 \mathrm{~m}^{2}$ de dispersión), los que en conjunto incluían 1.444 elementos arqueológicos. Los mapeos fueron recolectados y se relevaron espacialmente utilizando nivel óptico, información que permitió elaborar la topografía del sitio (Figura 4). Dentro del sitio se detectaron dos áreas con concentración de materiales, que denominamos PA68.1. y PA68.2., de $64 \mathrm{~m}^{2}$ y $187 \mathrm{~m}^{2}$, respectivamente. Dentro de estas, y donde la densidad de materiales era mayor, se realizó la recolección intensiva a partir de Unidades de Recolección Superficial Sistemática (URSS), tarea que implicó cuadricular el sector a intervenir en unidades de $1 \mathrm{~m}^{2}$ y la realización de mapeos. Posteriormente, se realizaron excavaciones en tres URSS que presentaban gran densidad de material.
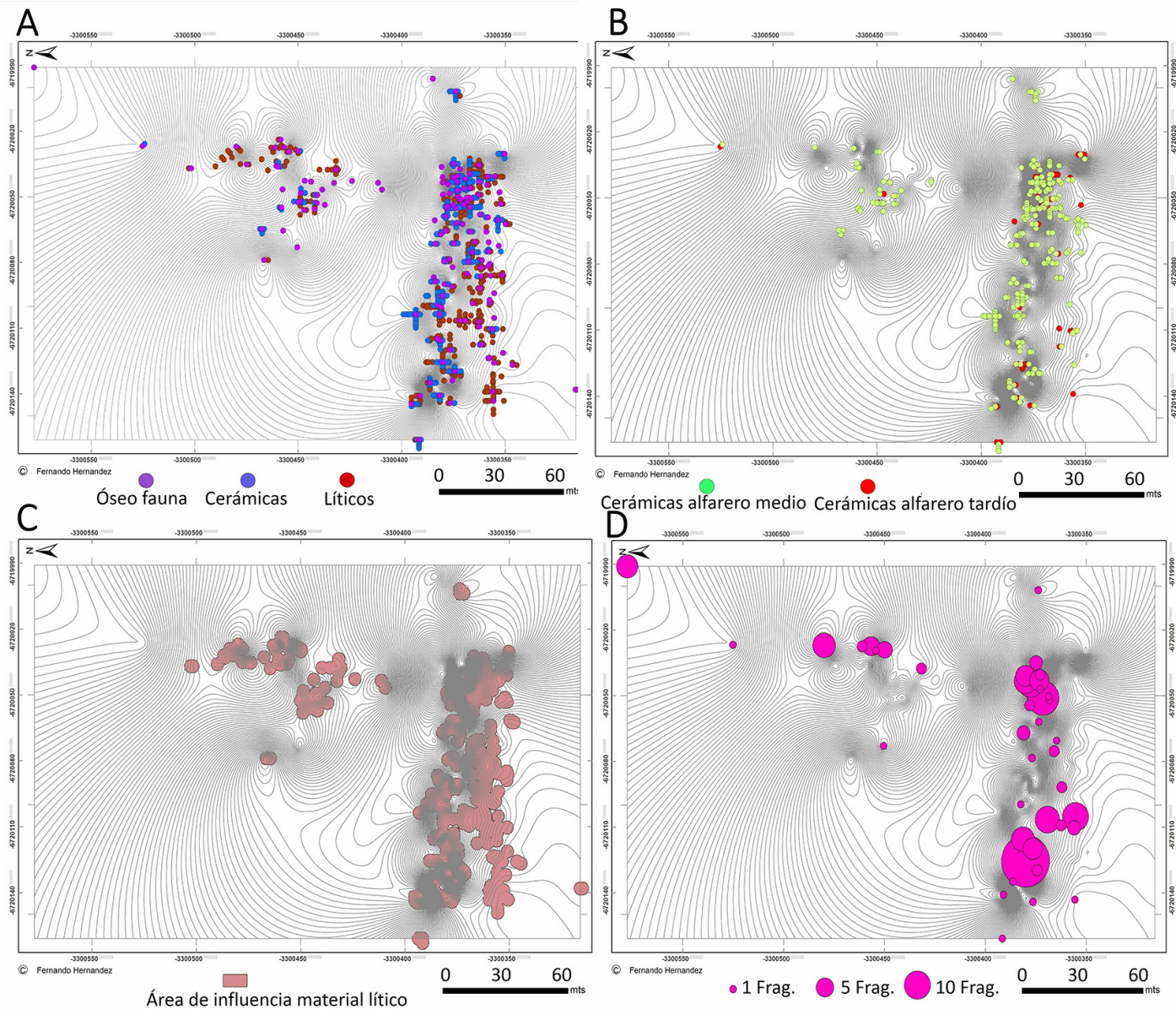

Figura 4. Topografía del PA68 y distribución de materiales en superficie. (A) Total de materiales mapeados; (B) cerámica (según tipos de los periodos Alfarero Medio y Tardío); (C) lítico; (D) arqueofauna, distribuciones con agrupaciones de cantidad de fragmentos.

PA68 topography and surface materials layout. (A) Total mapped materials; (B) ceramics (by types of the Middle and Late Pottery periods); (C) lithic; (D) archaeofauna, layouts with clusters of quantity of fragments. 
Las cuadrículas tenían $2 \mathrm{~m}^{2}$ cada una y se excavaron hasta los $75 \mathrm{~cm}$ de profundidad (en niveles de $5 \mathrm{~cm}$ de profundidad máxima), considerando las posibles diferencias estratigráficas. Se tamizó todo el sedimento arenoso en columnas de zarandas con mallas entre $0,7 \mathrm{~mm}$ y $0,3 \mathrm{~mm}$, y se recuperaron fragmentos de cerámica, líticos, restos zooarqueológicos y arqueobotánicos (principalmente carbones).

De los trabajos de prospección y excavación, se recuperó un total de 16.000 elementos. Los estudios arqueofaunísticos se centraron en aspectos tafonómicos generales de identificación y cuantificación $(\mathrm{N}=14.092)$, y se adoptaron los criterios de análisis sintetizados por Mengoni Goñalons (2010). Las determinaciones taxonómicas de los peces se hicieron en base a la colección de referencia existente en el Centro de Investigaciones Ruinas de San Francisco, Área Fundacional de Mendoza. Sobre la base de la riqueza taxonómica y la sumatoria de NMI, se estimó la abundancia relativa de individuos por especie. Con el programa PAST se calculó el índice de Shannon-H, para analizar la diversidad. También se calcularon los Índices de Dominancia y de Diversidad de Simpson, ya que este último permite medir el grado de dominancia que tiene un taxón en particular en el conjunto total del sitio (Mengoni Goñalons 2010). Para el estudio de los otolitos, se siguieron los criterios planteados por Wheeler y Jones (1989) e Higham y Horn (2000), también aplicados por Cahiza (2003a) en otros sitios de la región.

El estudio de los materiales líticos $(\mathrm{N}=1.137)$ se abocó a conocer aspectos del sistema de producción por medio de análisis tecnotipológicos de elementos a partir del cruce de variables como el tipo derivado de diferentes acciones de talla en el proceso de producción (Aschero 1983). Por su parte, la determinación macroscópica de materias primas líticas (MP), se realizó en base a las fuentes que son mapeadas desde hace varios años en diferentes ambientes generales: Planicie (MPL), Precordillera (MPR), Sierras Pampeanas (MPS) e indeterminadas (MPI) (Chiavazza 1995, 2001; Chiavazza y Cortegoso 2004; Cortegoso et al. 2017). El análisis de diversidad de materias primas se realizó en base a la aplicación del índice de diversidad de Simpson.

Los carbones vegetales fueron pesados y se realizaron cuatro dataciones radiocarbónicas. Los resultados de estos análisis se sumaron a los obtenidos del análisis de los estilos tecnológicos de la cerámica del sitio (Prieto-Olavarría et al. 2016). Para el análisis estadístico de la cronología, se utilizó el programa
CALIB REV. 7.0.4. (Stuiver et al. 2005), que permite convertir la edad de radiocarbono en años calendario y calibrarlos mediante el cálculo de una distribución de probabilidad de la edad verdadera de la muestra, permitiendo definir si las cuatro dataciones del sitio se ubican o no estadísticamente en un mismo rango cronológico por medio de porcentajes de coincidencia o diferencia (al 95\%). Para su realización, las dataciones del sitio se incorporaron dentro de un conjunto de 58 fechados propios para todo el norte de Mendoza (Prieto-Olavarría et al. 2017).

\section{Resultados}

Del total de elementos recuperados, $13.594(91 \%)$ se distribuyen en la superficie de $44.000 \mathrm{~m}^{2}$, lo que supone la densidad de 0,31 elementos arqueológicos por $1 \mathrm{~m}^{2}$. El mapeo con nivel óptico se realizó sobre 9\% del total de materiales (Tabla 1). Por su parte, la superficie de las URSS suma $251 \mathrm{~m}^{2}(0,57 \%)$ y se mapeó el $91 \%$ del total de los materiales de superficie, lo que muestra concentraciones importantes $(69 \%$ en PA68.1. y 11\% en PA68.2.), con un índice de 53 ea/ $\mathrm{m}^{2}$ (Figura 4A, B, C y D).

En las excavaciones, se recuperaron 1.411 elementos $(8,9 \%)$ en 15 niveles, los que se concentraban principalmente en los primeros $3 \mathrm{~cm}$, aunque se hallaron restos hasta los $65 \mathrm{~cm}$. No se detectaron cambios en la estratigrafía y la matriz corresponde a arenas eólicas. El mayor peso de carbones se recuperó entre los 25 y $30 \mathrm{~cm}$ de profundidad, lo que coincide con las tendencias de materiales que muestran una concentración en los niveles 4, 5 y 6 (Figura 5).

\section{Cronología}

La estimación cronológica en los sitios superficiales de la Planicie NE de Mendoza constituye un problema complejo con impacto directo en el desarrollo del conocimiento arqueológico (Chiavazza 2009). El hecho de que el registro se encuentre en superficie y contenido en sedimentos arenosos eólicos, genera palimpsestos que permiten trabajar dentro de márgenes temporales solo aproximados, por lo cual las tipologías cerámicas contribuyen a analizar preliminarmente la cronología del sitio (Figura 6). El análisis de este material, permitió observar mayor cantidad de restos del período Alfarero Medio respecto del Tardío (Porta y Bontorno 2015; Prieto-Olavarría et al. 2016). Es interesante observar las distribuciones de los fragmentos cerámicos considerando el peso 
Tabla 1. Cantidad de materiales recuperado por sector en el sitio PA68. URSS = Unidad de Recolección

Superficial Sistemática; EXCAV = Excavación; ea/ $\mathrm{m}^{2}$ = elemento arqueológico por metro cuadrado;

$\mathrm{N} \mathrm{CH}=$ cantidad de cáscaras de huevo; (1) indica superficie intervenida dentro del área total del sitio: $44.000 \mathrm{~m}^{2}$.

Number of materials by sector recovered at the PA68 site. URSS = Systematic Surface Collection Unit (SSCU);

EXCAV = Excavation; $\mathrm{ea} / \mathrm{m}^{2}=$ archaeological element per square meter; $\mathrm{N} C H=$ quantity of eggshells;

(1) indicates surface area intervened within the total area of the site: $44,000 \mathrm{~m}^{2}$.

\begin{tabular}{|c|c|c|c|c|c|c|c|c|}
\hline \multirow[b]{2}{*}{$\begin{array}{c}\text { Procedencia } \\
\text { y ea } / \mathrm{m}^{2}\end{array}$} & \multicolumn{8}{|c|}{ Cantidad de materiales (N) } \\
\hline & $\begin{array}{c}\text { Cerámica } \\
\text { (tamaño mayor } \\
\text { a } 0,5 \mathrm{~cm} \text { ) }\end{array}$ & $\begin{array}{c}\text { Cerámica } \\
\text { (tamaño menor } \\
\text { a } 0,5 \mathrm{~cm} \text { ) }\end{array}$ & Lítico & Óseo ident. & $\mathrm{NCH}$ & Astillas & Total & $\begin{array}{c}\text { Superficie } \\
\text { intervenida } \\
\text { y ea/m }{ }^{2}\end{array}$ \\
\hline MAPEOS & 400 & 85 & 480 & 20 & 390 & 50 & 1425 & $44.000 \mathrm{~m}^{2}$ \\
\hline URSS PA68.1. & 79 & 57 & 410 & 1.132 & 3.052 & 6.469 & 11199 & $64 \mathrm{~m}^{2}(1)$ \\
\hline EXCAV. PA68.1. & 18 & 23 & 56 & 158 & 609 & 100 & 964 & $4 \mathrm{~m}^{2}(1)$ \\
\hline URSS PA68.2. & 51 & 42 & 174 & 177 & 443 & 1080 & 1967 & $187 \mathrm{~m}^{2}(1)$ \\
\hline EXCAV. PA68.2. & 2 & 14 & 17 & 108 & 187 & 117 & 445 & $2 \mathrm{~m}^{2}(1)$ \\
\hline Sub Totales & 550 & 221 & 1.137 & 1.595 & 4.681 & 7.816 & 16000 & $44.000 \mathrm{~m}^{2}$ \\
\hline $\mathrm{Ea} / \mathrm{m} 2$ & 0,012 & 0,005 & 0,02 & 0,03 & 0,10 & 0,17 & - & $0,36 \mathrm{ea} / \mathrm{m}^{2}$ \\
\hline
\end{tabular}
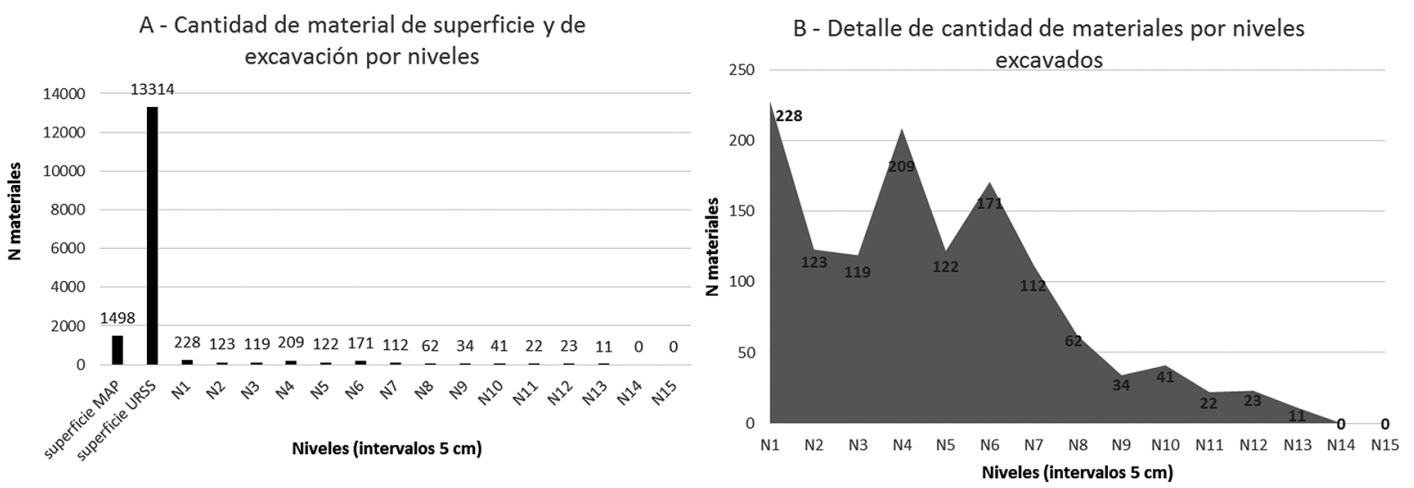

Figura 5. (A) Distribución del material arqueológico del PA68, en superficie y por niveles excavados (N); (B) Detalle de las cantidades recuperadas por niveles excavados. URSS = Unidades de Recolección Superficial Sistemática.

(A) Layout of the PA68 archaeological material on the surface and by excavated levels $(N)$; $(B)$ Detail of the quantities recovered by excavated levels. URSS $=$ Systematic Surface Collection Units.

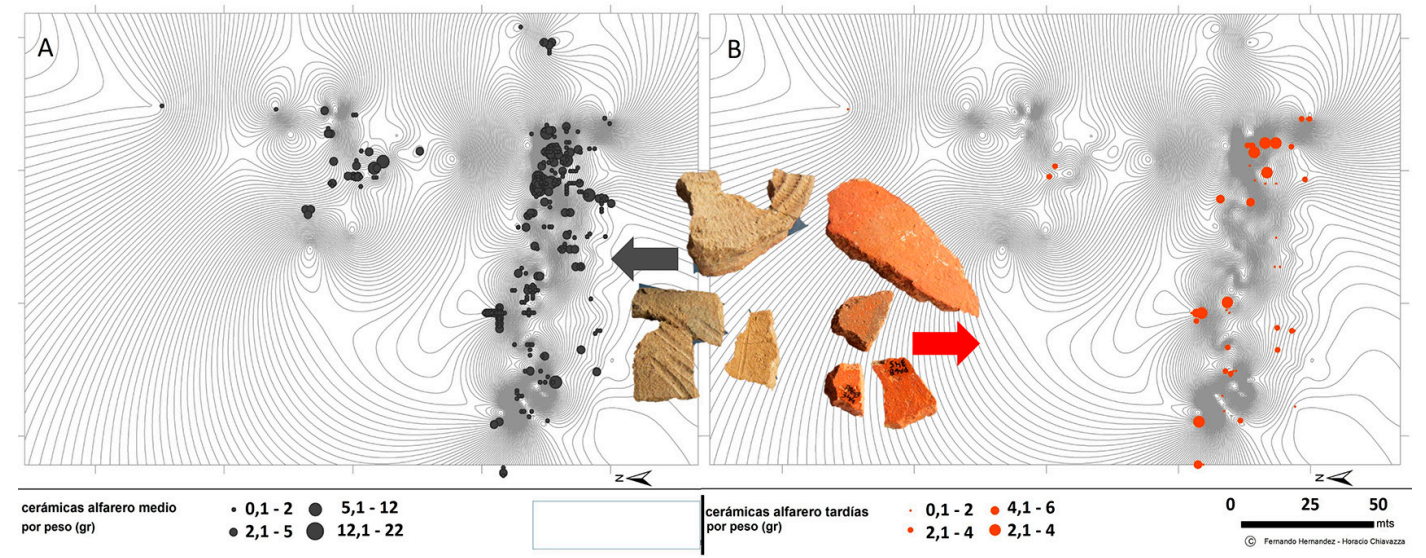

Figura 6. Distribución de fragmentos según tipologías cerámicas del norte de Mendoza en el PA68. (A) periodo Alfarero Medio (cerámica Agrelo y Grupo Gris Marrón); (B) periodo Alfarero Tardío (Viluco Inca Mixto).

Layout of fragments by pottery typologies of northern Mendoza in the PA68. (A) Middle Pottery period (Agrelo pottery and Grey Brown Group); (B) Late Pottery period (Mixed Inca Viluco). 
(agrupaciones a intervalos de menos de $1 \mathrm{~g}$; más de $1 \mathrm{~g}$; de $1,1 \mathrm{~g}$ hasta $10 \mathrm{~g}$, del total de $1.163 \mathrm{~g}$ ) (Figura 6), ya que aunque los fragmentos del periodo Medio tienen mayor concentración, sus áreas de dispersión coinciden con la del Tardío, por lo cual no es posible segregar áreas de ocupación diacrónica (Figura 4 B), como sí se observó en sitios de Lagunas (Cahiza 2003b).

De acuerdo a los antecedentes, cuando excepcionalmente se recupera material enterrado en sitios de la planicie, los niveles de integridad suelen ser muy bajos. En el PA68 realizamos cuatro fechados sobre el carbón vegetal recuperado de las cuadrículas excavadas (Tabla 2) y que se hallaban asociados a restos óseos termoalterados y concreciones de sedimento arcilloso enrojecidos, que serían resultado de eventos de combustión en estos sectores de mayor densidad de materiales. En total, se recuperaron $326 \mathrm{~g}$ de carbón, distribuidos en un volumen de $0,039 \mathrm{~m}^{3}$ de sedimentos excavados en 30 niveles (86,2\% en la excavación del PA68.1 y $17,3 \%$ en la excavación del PA68.2) (Figura 7). Las muestras del PA68.1 proceden de una matriz arenosa y la del PA68.2. presentaba arena y contenido de limo. Sin embargo, no es posible considerar que los contextos se encontraban en posición primaria, sino que son el resultado de procesos de alteración por la alternación de cubrimiento y exposición superficial propia de la dinámica de las dunas.

Se analizaron estadísticamente las correspondencias cronológicas de las cuatro dataciones y se identificaron dos componentes que concuerdan con los datos existentes a nivel regional, coincidentes además con las estimaciones temporales de los tipos cerámicos

Tabla 2. Fechados radiocarbónicos del PA68. *Calibración Programa CALIB 7.0.0 Usado en conjunción con Stuiver and Reimer, 1993 según informe LATYR.

Se resaltan fechas temprana y tardía extremas. $\delta^{13} \mathrm{C}$ (estimado para cada muestra) $=-24 \pm 2 \%$.

PA68 radiocarbon dating. * CALIB 7.0.0 Calibration Program used together with Stuiver and Reimer, 1993 as reported by LATYR. Extreme early and late dates are highlighted. $\delta^{13} \mathrm{C}$ (estimated for each sample) $=-24 \pm 2 \%$.

\begin{tabular}{|c|c|c|c|c|c|c|c|c|c|}
\hline Sector & Cuadrícula & Nivel & $\begin{array}{l}\text { Profundidad } \\
\quad(\mathrm{cm})\end{array}$ & $\begin{array}{c}\text { Sector } \\
\text { duna }\end{array}$ & Material & $\begin{array}{l}\text { Datación } \\
\text { antes del } \\
\text { presente }\end{array}$ & $\begin{array}{c}\text { Rango de } \\
1 \sigma \text { cal. AD } \\
\text { (comienzo y fin)* }\end{array}$ & $\begin{array}{c}\text { Datos } \\
\text { laboratorio }\end{array}$ & $\begin{array}{l}\text { Lapso } \\
\text { regional }\end{array}$ \\
\hline PA68.1. & E7 & 2 & 10 & Alto & Carbón vegetal & $1160 \pm 80$ & 858-1020 & LP3105 & \multirow{2}{*}{$\begin{array}{c}\text { Componente } \\
\text { VII }\end{array}$} \\
\hline PA68.2. & K3 & 6 & 30 & Alto & Carbón vegetal & $1050 \pm 80$ & $985-1150$ & LP3111 & \\
\hline PA68.1. & E6 & 7 & 35 & Alto & Carbón vegetal & $880 \pm 60$ & 1159-1266 & LP3093 & \multirow{2}{*}{$\begin{array}{l}\text { Componente } \\
\text { VIII }\end{array}$} \\
\hline PA68.1. & $\mathrm{C} 2$ & 4 & 20 & Bajo & Carbón vegetal & $840 \pm 70$ & $1180-\mathbf{1 2 8 3}$ & LP3120 & \\
\hline
\end{tabular}

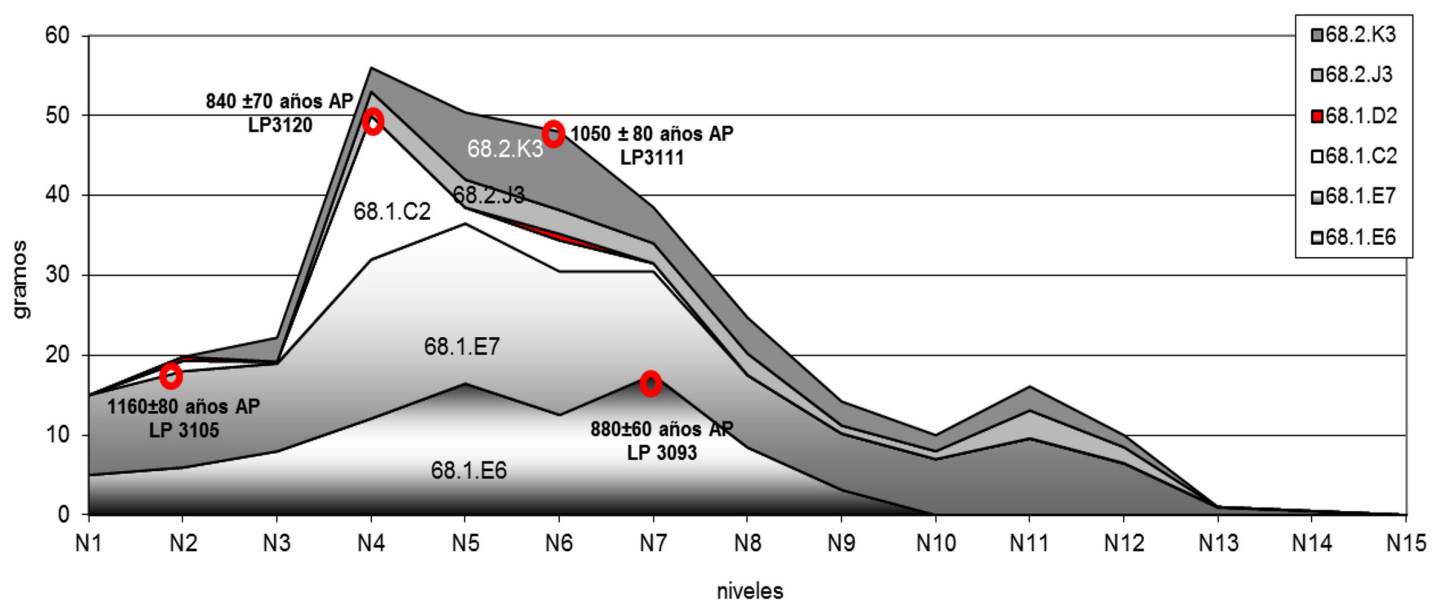

Figura 7. Relación de peso de carbón recuperado por niveles en las excavaciones del PA68 con referencia a las dataciones obtenidas (anillos rojos).

Weight ratio of coal recovered by levels in the PA68 excavations with reference to the datings obtained (red rings). 
(Prieto-Olavarría et al. 2016). De acuerdo con tales criterios se diferenciaron diez componentes y las dataciones del PA68 se agruparon en los componentes CVII y CVIII ${ }^{1}$, por lo cual podría proponerse exploratoriamente la existencia de dos ocupaciones durante el periodo Alfarero Medio, con un breve intervalo entre ambas, el primero entre los años calendáricos ca. 858 y 1150 AD y el segundo entre los ca. 1159 y los $1283 \mathrm{AD}$, como fechas extremas calibradas (Tabla 2, en negrita). Por otra parte, la presencia de cerámica Viluco Inca Mixto permite inferir una ocupación posterior del sitio, durante el periodo Alfarero Tardío (en torno a los ca. 400 años AP), la que correspondería a la movilidad estratégica que desarrollaron las poblaciones asentadas al oeste, en el Valle de Mendoza, durante el siglo XVI y que corresponde al lapso signado por las condiciones áridas de la PEH (Chiavazza 2015b; Prieto-Olavarría et al. 2016). A partir de estos datos se define un marco temporal de ocupaciones entre aproximadamente los ca. 400 y 1200 años AP, las que, si bien pueden desagregarse en tres componentes, no permiten discriminar los materiales dentro del rango de 800 años, salvo la evidencia cerámica.

\section{Análisis de Arqueofauna}

El conjunto arqueofaunístico, incluidos huesos, dientes y cáscaras de huevo, es el más numeroso, ya que asciende a 14.092 especímenes óseos, de los cuales el $11 \%$ son reconocibles en algún nivel taxonómico y el $89 \%$ son indiferenciados (en general pequeñas astillas). La elevada fragmentación es indicativa de los procesos postdepositacionales que afectaron la muestra (Guardia y Francalancia 2015). Se contabilizó un NISP de 1.595 especímenes que se agrupan en 24 identificaciones faunísticas en algún nivel taxonómico, con un índice de riqueza de NTAXA $=15$. A esto se suman los 7.816 especímenes que no fueron identificados, más 4.681 cáscaras de huevo diferenciadas entre las de ñandú (sensu Quintana 2008) y aves en general.

\section{Aspectos tafonómicos}

Todos los huesos presentan algún grado de meteorización y/o alteración. Un estudio tafonómico específico sobre especímenes de micromamíferos identificados a nivel taxonómico permitió identificar remodelaciones por procesos digestivos de rapaces y definirlos como ingresados al registro por agentes acumuladores no humanos (categorías 1 y 2 de modificación, sensu Andrews 1990 en López y Chiavazza 2019). No obstante, existen huesos de micromamíferos que indican el uso humano si se consideran las termonalteraciones y/o marcas y huellas (Chiavazza et al. 2014; Guardia y Francalancia 2015).

Las placas de armadillo halladas en superficie presentan mayor meteorización (blanqueo y estriados), en tanto que las mejor conservadas son las subsuperficiales (amarillentas y marrones) (Figura 8). En cuanto a la integridad, las relaciones entre mayor completitud y entierro son las más altas, a diferencia de las superficiales, que presentan menor porción conservada. Los porcentajes de termoalteración ascienden al 7,5\% de la muestra, entre placas quemadas (negras), calcinadas (blancas) y tostadas (marrones). En cuanto a los huesos de pescado, los mismos presentan diferentes porcentajes de fragmentación tanto entre los especímenes superficiales como en los enterrados (Figura 9).

El porcentaje de huesos de especies reconocibles con indicios de termoalteración total o parcial

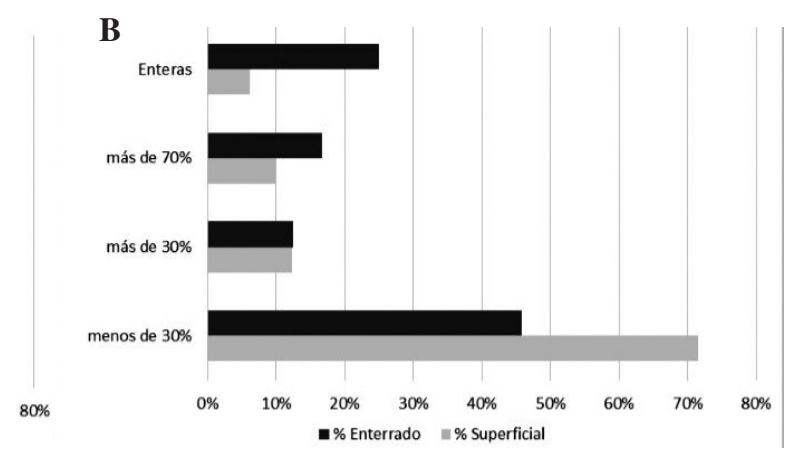

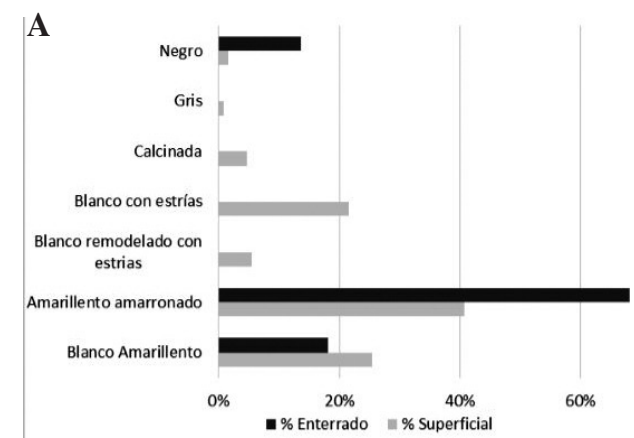

Figura 8. Análisis tafonómico en placas de armadillos según procedencia superficial o enterradas en el PA68. (A) estado y coloración; (B) integridad.

Taphonomic analysis in armadillo scales according to surface or subsoil origin in the PA68. (A) condition and coloring; $(B)$ entirety. 


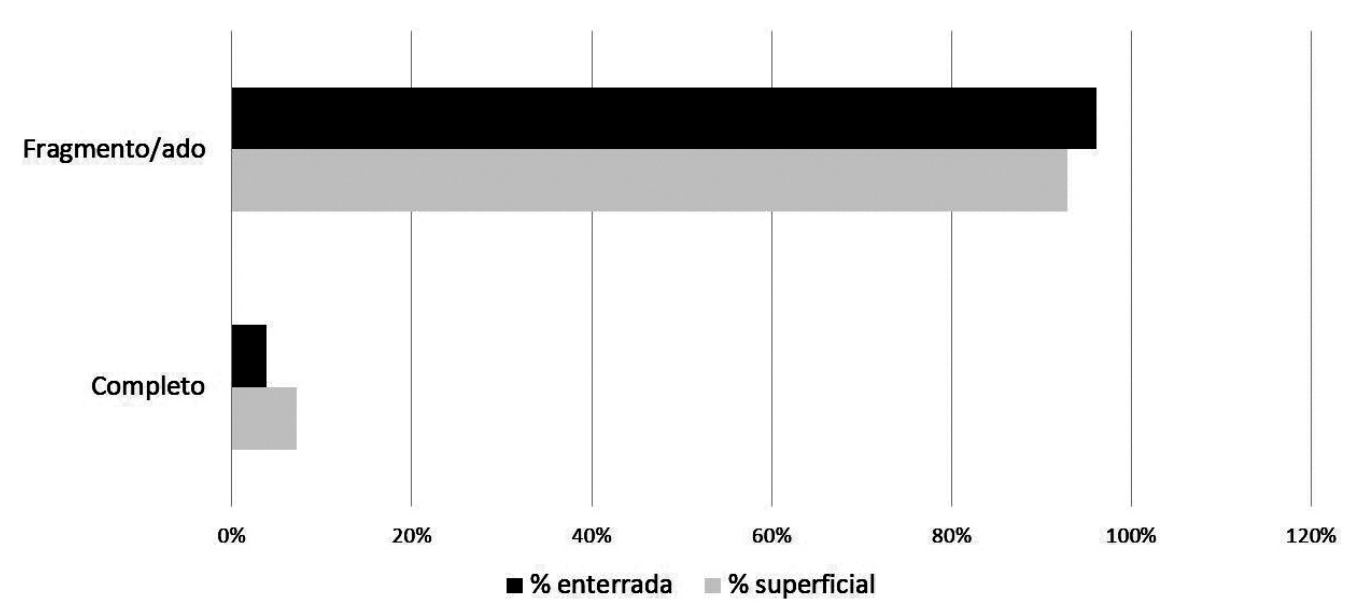

Figura 9. Porcentajes de huesos de pescado según completitud y procedencia superficial o enterrada en el PA68.

Percentage of fish bones by entirety and surface or buried origin in the PA68.

(quemados, tostados y/o calcinados) alcanza el 65\% $(\mathrm{N}=1.422)$ e involucra, en diferentes proporciones, a todas las reconocidas en algún nivel taxonómico (Tabla 3). El 24,7\% de las cáscaras de huevo presentan algún grado de termoalteración. El estudio de las astillas acompaña lo analizado en los especímenes reconocibles, ya que refiere a fauna pequeña con un $31,6 \%$ de fragmentos termoalterados (Tabla 3 ), lo que hace pensar en el uso humano de aves y roedores, independientemente que en el segundo caso se haya comprobado también el ingreso en egagrópilas de rapaces (López y Chiavazza 2019).

Las observaciones tafonómicas arrojan, de este modo, resultados consecuentes con las características depositacionales del sitio, con bajos niveles de integridad, aspecto observado recurrentemente en la Planicie NE de Mendoza.

\section{Aspectos taxonómicos}

El conjunto arqueofaunístico procede de los mapeos y las dos unidades de concentración (PA68.1. y PA68.2.). Si bien las cuantificaciones generales de NISP y el estado de los restos se consideraron para el sitio en general, la dispersión llevó a considerar las dos unidades más los mapeos como base para el cálculo de NMI.

En términos generales, se destaca la cantidad y predominio comparativo de huesos de peces, entre los que, de acuerdo a las frecuencias de NISP, predomina ampliamente Percichthys trucha, por sobre Odontesthes sp., Synbranchus marmoratus, Diplomystes sp. e indeterminados (Tabla 3). Para el análisis de las cáscaras de huevo $(\mathrm{N}=4.691$, equivalentes a $130 \mathrm{~g}$ ), se siguió la propuesta de determinación específica y cálculo de NMI de Quintana (2008) y se observó la predominancia de fragmentos de aves no identificadas $(\mathrm{N}=2.597$; $25 \mathrm{~g}$ ) en comparación con las de ñandú (Rhea americana $)(\mathrm{N}=2.094 ; 105,6 \mathrm{~g})$, aunque la relación se invierte considerando el peso. Entre los huesos de otros animales predominan los de tamaño pequeño, pero con gran disponibilidad en el área como las aves y micromamíferos propios de la provincia del Monte, y en ciertos casos con muy buen rendimiento en el contexto regional, como Dasipodidae, propuestos en segundo lugar del rankig local (Corbat 2015).

En el marco de la diversidad de especies representadas y con algunas evidencias de uso humano (marcas y termoalteraciones), destaca la cantidad de huesos de pescado, predominando la Perca Percichthys trucha sobre pejerrey Odontesthes sp., la anguila Synbranchus marmoratus y el bagre Diplomystes sp., respectivamente, con evidencias de termoalteración (quemado, tostado y calcinado) en el $75 \%$ de los casos (Tabla 3). Luego siguen animales de tamaño pequeño y en menor medida medianos. La tendencia predominante en los NISP de peces, seguida de aves y mamíferos de porte pequeño se mantiene en los cálculos de NMI, donde la perca domina claramente (Tablas 3 y 4).

Los análisis permitieron estimar una riqueza taxonómica de NTAXA = 15 y la sumatoria de NMI ascendió a 207 para todo el sitio PA68 (Tabla 4). Por otra parte, el índice de Shannon-H es de 0,8931, señalando baja diversidad. También se comprobó que el Índice de Dominancia es alto (cercano a 1), y 
Tabla 3. Abundancia taxonómica arqueofaunística y tafonomía del PA68. Los NISP corresponden a todo el sitio. Los NMI corresponden a los mapeos y las URSS excavadas. El N estado, corresponde a estado de alteración: normal (N); tostado (T); quemado $(\mathrm{Q})$; calcinado $(\mathrm{C})$. * Indica placas de coraza; ** indica cantidad de fragmentos; NC indica No Contabilizado. Archeofaunal taxonomic abundance and taphonomy of PA68. The NISPs correspond to the entire site. NISPs

correspond to mapping and excavated URSS (SSCU). The N state corresponds to the alteration state: normal (N); roasted $(T)$; burnt $(Q)$; calcined $(C)$. * Indicates shell plates; ** indicates number of fragments; NC means Not Counted.

\begin{tabular}{|c|c|c|c|c|c|c|c|c|c|c|}
\hline \multirow{2}{*}{ Nombre vulgar } & \multirow{2}{*}{ Género-especie } & \multirow{2}{*}{ NISP } & \multirow{2}{*}{$\begin{array}{c}\% \\
\text { NSIP }\end{array}$} & \multicolumn{4}{|c|}{$\mathrm{N}$ estado } & \multirow{2}{*}{$\begin{array}{c}\text { NMI } \\
\text { PA68.1 }\end{array}$} & \multirow{2}{*}{$\begin{array}{c}\text { NMI } \\
\text { PA68. } 2\end{array}$} & \multirow{2}{*}{$\begin{array}{l}\text { NMI } \\
\text { Map }\end{array}$} \\
\hline & & & & $\mathrm{N}$ & $\mathrm{T}$ & Q & $\mathrm{C}$ & & & \\
\hline Peludo & Chaetophratus villosus & $3(+26 *)$ & 0,20 & 25 & 3 & 0 & 1 & 1 & 0 & 1 \\
\hline Piche & Zaedyus pichyi & $32(+32 *)$ & 2,13 & 28 & 14 & 10 & 12 & 1 & 1 & 1 \\
\hline Piche & Tolypeutes matacus & $0(+2 *)$ & $\mathrm{NC}$ & 2 & 0 & 0 & 0 & 0 & 1 & 0 \\
\hline Armadillo & Dasypodidae sp. & $19(+90 *)$ & 1,26 & 75 & 14 & 12 & 9 & 1 & 1 & 1 \\
\hline Anguila & Synbranchus marmoratus & 19 & 1,26 & 5 & 11 & 1 & 2 & 1 & 1 & 0 \\
\hline Bagre & Diplomystes sp. & 5 & 0,33 & 1 & 0 & 2 & 2 & 1 & 1 & 0 \\
\hline Pejerrey & Odontesthes sp. & 61 & 4,6 & 7 & 42 & 7 & 5 & 2 & 1 & 0 \\
\hline Perca & Percichthys trucha & 899 & 60 & 224 & 513 & 62 & 73 & 153 & 11 & 7 \\
\hline Pescado & Pescado indeterminado & 7 & 0,46 & 6 & 1 & 0 & 0 & - & - & 0 \\
\hline Ave & Ave indeterminado & 132 & 8,80 & 42 & 27 & 42 & 21 & 4 & 2 & 0 \\
\hline Mamífero med & mamífero indeterminado mediano & 9 & 0,60 & 2 & 1 & 4 & 2 & 1 & 1 & 0 \\
\hline Mamífero peq & mamífero indeterminado pequeño & 37 & 2,46 & 2 & 14 & 8 & 8 & 1 & 1 & 1 \\
\hline Rana & Ranidae & 9 & 0,60 & 7 & 1 & 0 & 1 & 1 & 3 & 0 \\
\hline Guanaco & Lama sp. & 1 & 0,06 & 0 & 0 & 1 & 0 & 1 & 0 & 0 \\
\hline $\mathrm{s} / \mathrm{d}$ & Rodentia ind. & 196 & 13,07 & 65 & 63 & 30 & 35 & 3 & 1 & 0 \\
\hline Marmosa coligruesa pálida & Thylamys pallidior & 3 & 0,20 & 1 & 1 & 0 & 1 & 1 & 1 & 0 \\
\hline $\mathrm{s} / \mathrm{d}$ & Caviidae indet & 8 & 0,53 & 7 & 0 & 1 & 0 & 2 & 0 & 0 \\
\hline Cuy & Galea leucoblephar & 3 & 0,20 & 3 & 0 & 0 & 0 & 1 & 0 & 0 \\
\hline Tuco tuco & Ctenomys cf. C. mendocinus & 2 & 0,13 & 2 & 0 & 0 & 0 & 1 & 0 & 0 \\
\hline Tuco tuco & Ctenomyidae Histricomorfos & 1 & 0,06 & 1 & 0 & 0 & 0 & 1 & 0 & 0 \\
\hline s/d & Sigmodontinae & 17 & 1,13 & 17 & 0 & 0 & 0 & 2 & 0 & 0 \\
\hline Cuy & Microcavia australis & 16 & 1,06 & 13 & 0 & 0 & 3 & 2 & 1 & 0 \\
\hline $\mathrm{s} / \mathrm{d}$ & Reptil indeterminado & 20 & 1,33 & 5 & 12 & 0 & 3 & 3 & 1 & 1 \\
\hline Rhea sp. & Cáscaras de huevo** & 2.094 & $\mathrm{NC}$ & 1.342 & 518 & 234 & 0 & 1 & 1 & 1 \\
\hline Ave ind. & Cáscaras de huevo** & 2.597 & $\mathrm{NC}$ & 2.188 & 214 & 195 & - & - & - & - \\
\hline
\end{tabular}

Tabla 4. Especies y NTaxa, Número Mínimo de Individuos y cálculos de abundancia relativa, con resultados en cuanto a dominancia e índice de diversidad de Simpson del PA68. En negritas el índice de abundancia relativa de Percichtys trucha. Species and NTaxa, Minimum Number of Individuals and relative abundance estimates, with results for dominance and Simpson's diversity index of PA68. Relative abundance index of Percichtys trucha in bold.

\begin{tabular}{lrcr}
\hline \multicolumn{1}{c}{ Taxa } & NMI PA68 & Abundancia relativa (Pi) & \multicolumn{1}{c}{$\mathrm{Pi}^{2}$} \\
\hline Chaetophratus villosus & 2 & 0,00966184 & $9,3351 \mathrm{E}-05$ \\
Zaedyus pichyi & 3 & 0,01449275 & 0,00021004 \\
Tolypeutes matacus & 1 & 0,00483092 & $2,3338 \mathrm{E}-05$ \\
Synbranchus marmoratus & 2 & 0,00966184 & 0,00933512 \\
Diplomystes sp. & 2 & 0,00966184 & $9,3351 \mathrm{E}-05$ \\
Odontesthes sp. & 3 & 0,01449275 & 0,00021004 \\
Percichthys trucha & 171 & $\mathbf{0 , 8 2 6 0 8 6 9 6}$ & 0,68241967 \\
Ave & 6 & 0,02898551 & 0,00084016 \\
Ranidae & 4 & 0,01932367 & 0,0003734 \\
Lama sp. & 1 & 0,00483092 & $2,3338 \mathrm{E}-05$ \\
Thylamys pallidior & 2 & 0,00966184 & $9,3351 \mathrm{E}-05$ \\
Galea leucoblephar & 1 & 0,00483092 & $2,3338 \mathrm{E}-05$ \\
Ctenomys cf. C. mendocinus & 1 & 0,00483092 & $2,3338 \mathrm{E}-05$ \\
Microcavia australis & 3 & 0,01449275 & 0,00021003 \\
Reptil indeterminado & 5 & 0,02415459 & 0,00058344 \\
Sumatoria & 207 & Dominancia & 0,6945553 \\
NTaxa=15 & & Indice de Diversidad & 0,3054447 \\
\hline
\end{tabular}


consecuentemente, es bajo el de Diversidad. Estos resultados indican la dominancia por abundancia relativa de peces, específicamente de Percichthys trucha. Gran parte de los especímenes $(81,9 \%)$ se concentra en el sector PA68.1. (Tabla 3).

\section{Análisis de otolitos}

El estudio realizado sobre los otolitos, permitió observar que de 308 elementos, $\mathrm{N}=20(6,4 \%)$ corresponden a Odontesthes sp. y N =288, $(93,6 \%)$ a Percichthys trucha. Para el estudio de anillos de crecimiento solo se tomaron otolitos enteros: 23 de Percichthys trucha; 18 de Odontesthes sp. Con ello se pudo establecer, según el último anillo de crecimiento (hialino u opaco), que los de Percichthys corresponden tanto a la estación cálida como a la fría, mientras que los de Odontesthes se asocian predominantemente a la fría (Figura 10).

\section{Tecnología sobre restos óseos}

Se detectaron elementos óseos de fauna pequeña con evidencias de haber participado como materia prima en procesos tecnológicos aún no determinados, pero que sugieren la elaboración de cuentas. Huesos largos tubulares de pequeño tamaño tienen marcas perimetrales de cortes transversales que, en dos casos, presentan regularidad cada $7 \mathrm{~mm}$ aproximadamente. Estos se concentran en dos cuadrículas del PA68.1. (Chiavazza et al. 2014; Guardia y Francalancia 2015).

\section{Análisis lítico}

De acuerdo al análisis tecnológico, observamos que las acciones representadas por los residuos indican la presencia de todas las etapas del proceso de talla, aunque con diferentes frecuencias (Tabla 5 y Figura 11). Los 1.137 productos de talla recuperados, presentan restos de adelgazamiento secundario y fundamentalmente de retoque, magnificado por la cantidad de microlascas e hipermicrolascas, aspecto poco recurrente en sitios de la planicie (Chiavazza 2007), y seguido de restos derivados del descarte. En tercer lugar, se encuentra el adelgazamiento primario seguido de la reducción inicial, adquisición, instrumentos y reactivación, respectivamente. Los restos vinculados con la adquisición, núcleos y restos con corteza además de descartes, suman un 39,8\%, lo que indica una acumulación de materias primas que supusieron un buen reservorio para producir instrumentos. Esto es relevante si se considera que el sitio se encuentra lejos de las fuentes de provisión (entre 30 y $40 \mathrm{~km}$ de distancia en promedio), por lo cual la concentración de estas materias hace previsible su disponibilidad futura.

La tecnología lítica en el sitio se centró en materias primas procedentes de múltiples ambientes y de variada calidad, tanto de grano fino como grueso, más o menos tenaces, así como también de dureza y fragilidad variable. En términos cuantitativos se pueden comparar tendencias en base a dos medidas: por cantidad de restos o por el peso de las materias primas. En el

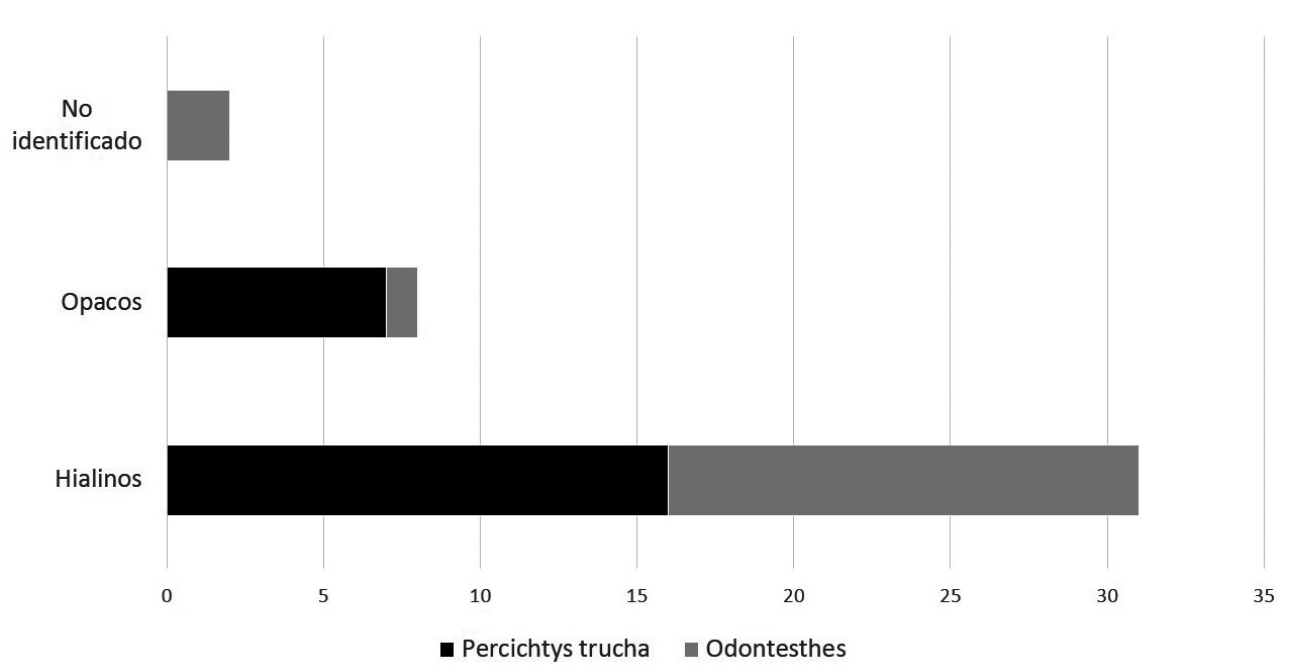

Figura 10. Últimos anillos de crecimiento en otolitos enteros recuperados en el PA68.

Last growth rings in entire otoliths recovered in the PA68. 
Tabla 5. PA 68. Proceso de reducción según cantidad y porcentaje de productos asociados a materias primas de diferente proveniencia.

PA 68. Reduction process by quantity and percentage of products associated with raw materials of different provenance.

\begin{tabular}{|c|c|c|c|c|c|c|c|c|}
\hline $\begin{array}{l}\text { Proceso de reducción según } \\
\text { porcentaje de productos asociados }\end{array}$ & MPL & $\% \mathrm{MPL}$ & MPR & $\% \mathrm{MPR}$ & MPS & $\%$ MPS & IND & $\%$ IND \\
\hline Adquisición & 61 & 12,8 & 10 & 2,51 & 9 & 3,6 & 5 & 45,5 \\
\hline Reducción inicial y preparación de núcleo & 32 & 6,7 & 24 & 6,03 & 38 & 15,1 & 1 & 9,1 \\
\hline Adelgazamiento primario & 42 & 8,8 & 29 & 7,29 & 49 & 19,4 & 0 & 0,0 \\
\hline Adelgazamiento secundario y retoque & 161 & 33,8 & 276 & 69,35 & 64 & 25,4 & 0 & 0,0 \\
\hline Reactivación & 0 & 0,0 & 8 & 2,01 & 0 & 0,0 & 0 & 0,0 \\
\hline Instrumento & 14 & 2,9 & 12 & 3,02 & 30 & 11,9 & 1 & 9,1 \\
\hline Descarte (fi) & 166 & 34,9 & 39 & 9,80 & 62 & 24,6 & 4 & 36,4 \\
\hline Total & 476 & 100 & 398 & 100 & 252 & 100 & 11 & 100 \\
\hline
\end{tabular}

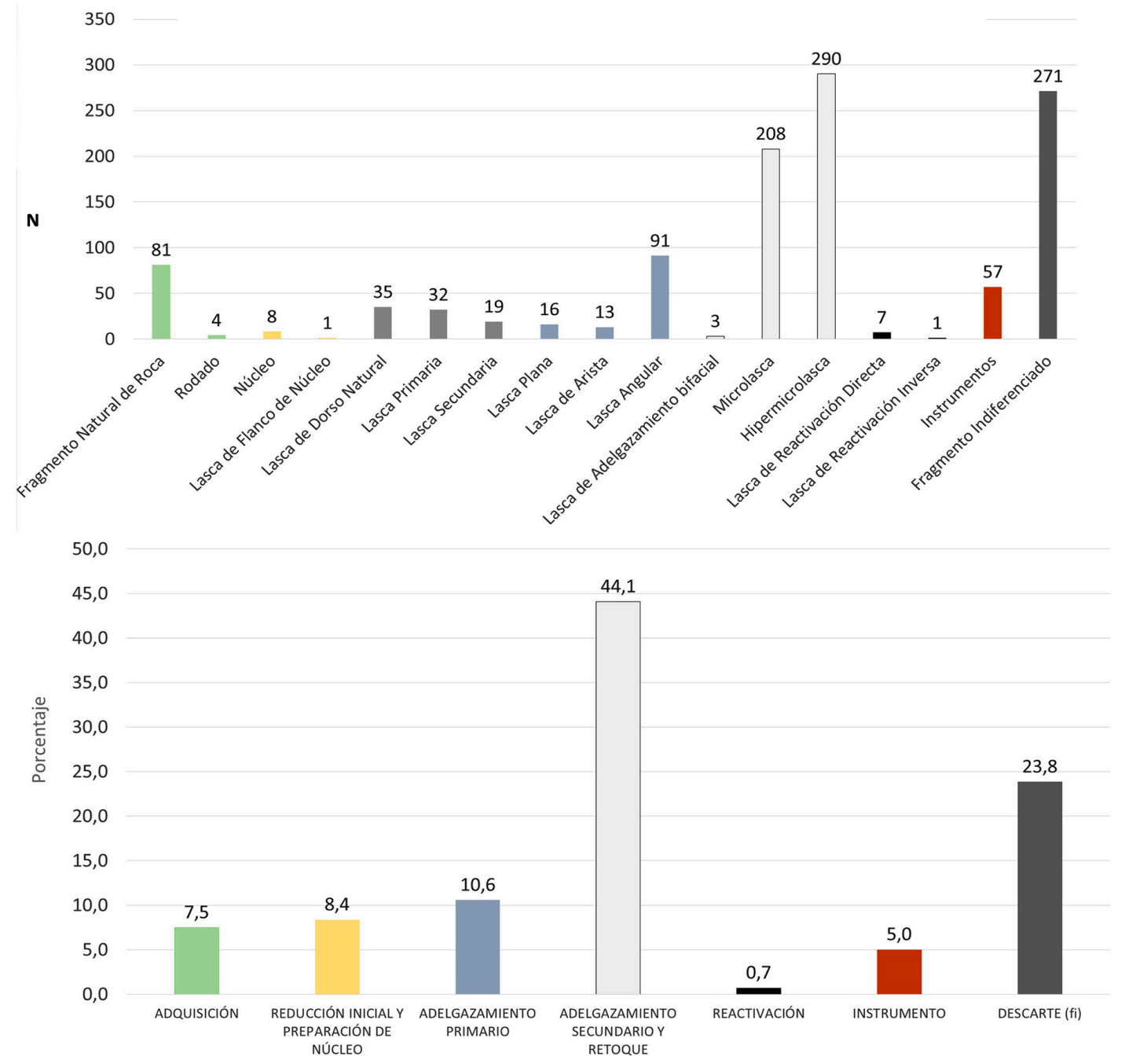

Figura 11. Cantidad de productos de talla lítica por tipo (arriba) y agrupaciones porcentuales dentro del proceso de producción (abajo) en la PA68.

Quantity of lithic carved products by type (top) and percentage groupings within the production process (bottom) in the PA68. 
primer caso, las materias MPL predominan con un $41,8 \%$ del total seguidas de MPS (35\%), MPR (22\%) y MPI (1\%), respectivamente. Al considerar los pesos, las MPL mantienen la clara primacía con un $68,8 \%$, pero el segundo lugar cambia a las materias primas MPS $(31,9 \%)$ y al tercer lugar pasan las MPR $(3,2 \%)$, mientras que las MPI (2\%) se mantienen en cuarta posición. Al comparar las cantidades y los pesos de los tipos de materias primas (Figura 12), se observa que en los subtipos de MP estas tendencias varían sustancialmente.

Para analizar la diversidad de materias primas, se aplicó el índice de diversidad de Simpson a 1.137 piezas, contando para ello con 50 tipos y subtipos de las mismas. Los resultados indican que la diversidad es muy alta (ID $=0,862121539$ ) y en consecuencia presenta muy baja homogeneidad ( $\mathrm{D}=0,13787846114)$. El índice de abundancia relativa Pi más alto correspondió a la variante de Silícea I (0,28671943729). Aplicamos estos índices solo a los 11 tipos generales de materias primas (sobre 1.126 piezas, ya que se excluyeron las indiferenciadas) y la tendencia se mantuvo con bajo índice de dominancia ( $\mathrm{D}=0,27573674428)$ y alto índice de diversidad (ID = 0,724263256).

Los instrumentos ( $\mathrm{N}=57)$ equivalen a un $5 \%$ del total del conjunto lítico (un instrumento cada 18,9 restos de talla). Predominan los elaborados sobre MPS (52,6\%), por sobre los de MPL (24,6\%) y MPR $(21,1 \%)$, mientras que los de MPI representan solo el $1,8 \%$. En cuanto a los diseños, en general predominan los informales $(64,9 \%)$ sobre los de diseño formal
$(35,1 \%)$ y se marca una notable diferencia entre los informales de MPS $(38,6 \%)$ (Figura 13).

Los instrumentos agrupados en dos conjuntos generales, con filo y sin filo, muestran un predominio de los primeros $(70,2 \%)$ sobre los segundos $(29,8 \%)$. Dentro de los instrumentos con filo, los que poseen filos naturales con rastros complementarios suman el $17,5 \%$ y aquellos con retoques el $52,6 \%$. Los 40 instrumentos con filo se dividieron entre los mayores y menores de $45^{\circ}$, arrojando porcentajes del $82,5 \%$ y $17,5 \%$, respectivamente. El retoque que predomina es el marginal corto $(75 \%)$ sobre el marginal largo $(17,2 \%)$, el extendido $(3,4 \%)$ y el total $(3,4 \%)$. Entre los artefactos no retocados que comprometieron acciones de moler, abradir/ pulir, machacar, percutir y adornar, predominan los de molienda (Figura 14) ${ }^{2}$. Se observa que los instrumentos del sitio se relacionan con actividades de procesamiento, donde se destacan los filos con retoques marginales y discontinuos, con ángulos mayormente superiores a los $45^{\circ}$. Raspar, raer y cortar, aparecen consecuentemente como las acciones que dejaron mayor evidencia instrumental, seguidos por la molienda. Es llamativa la ausencia de puntas de proyectil, aspecto ya documentado en otros sitios de la región, especialmente en tierras bajas y para el mismo lapso (Chiavazza 2007, 2015b).

La ausencia de diseños formales y baja estandarización de los instrumentos expresaría una estrategia tecnológica expeditiva para uso en el sitio, aunque las evidencias de talla secundaria

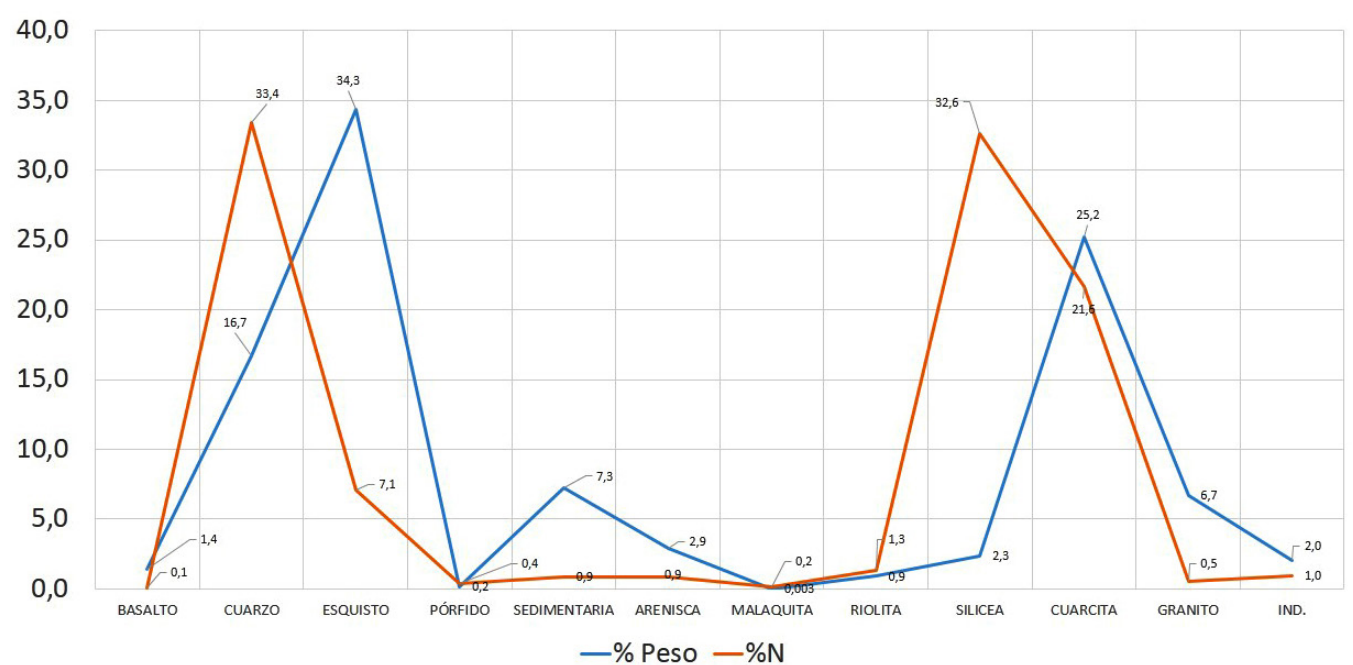

Figura 12. Porcentajes comparados de materias primas líticas (MP) según cantidad y peso en el PA68.

Comparative percentages of lithic raw materials (MP) by quantity and weight in PA68. 


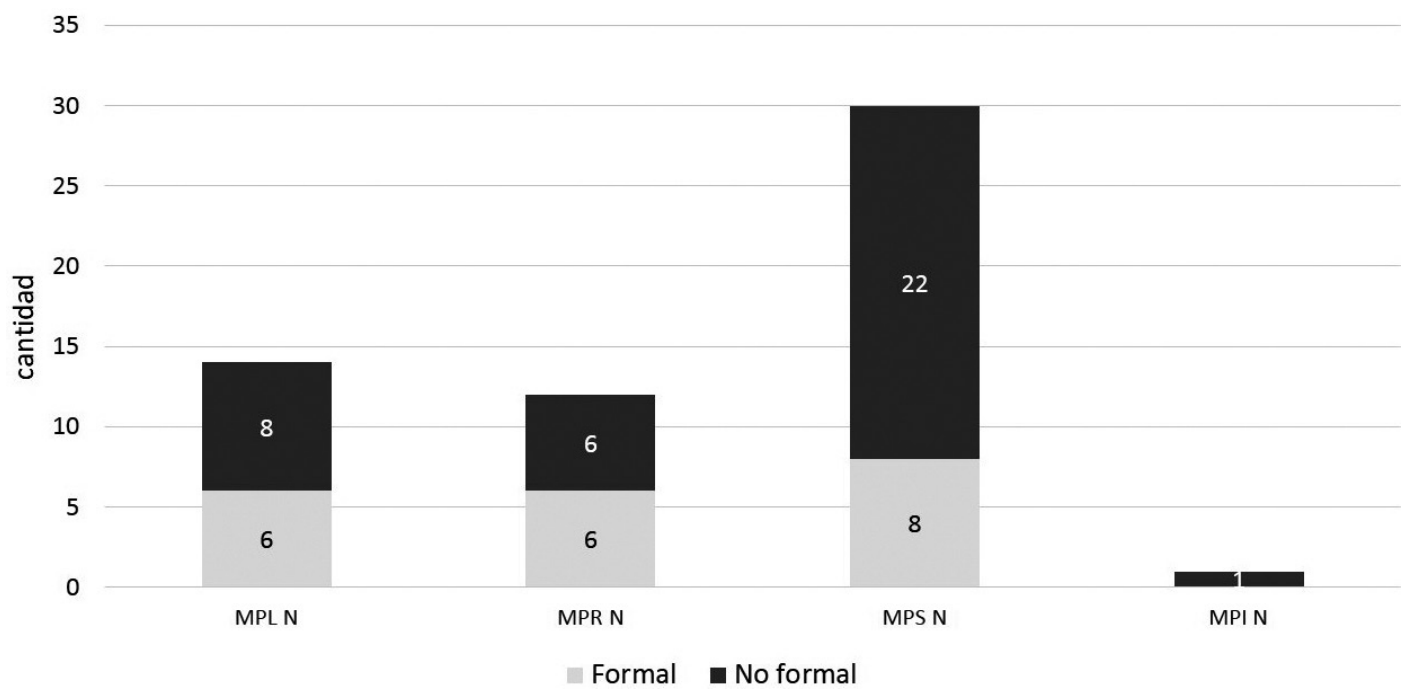

Figura 13. Comparación de cantidades de instrumentos líticos (N=57) según diseño y materias primas en el PA68.

Comparison of lithic instrument quantities $(N=57)$ according to design and raw materials in PA68.

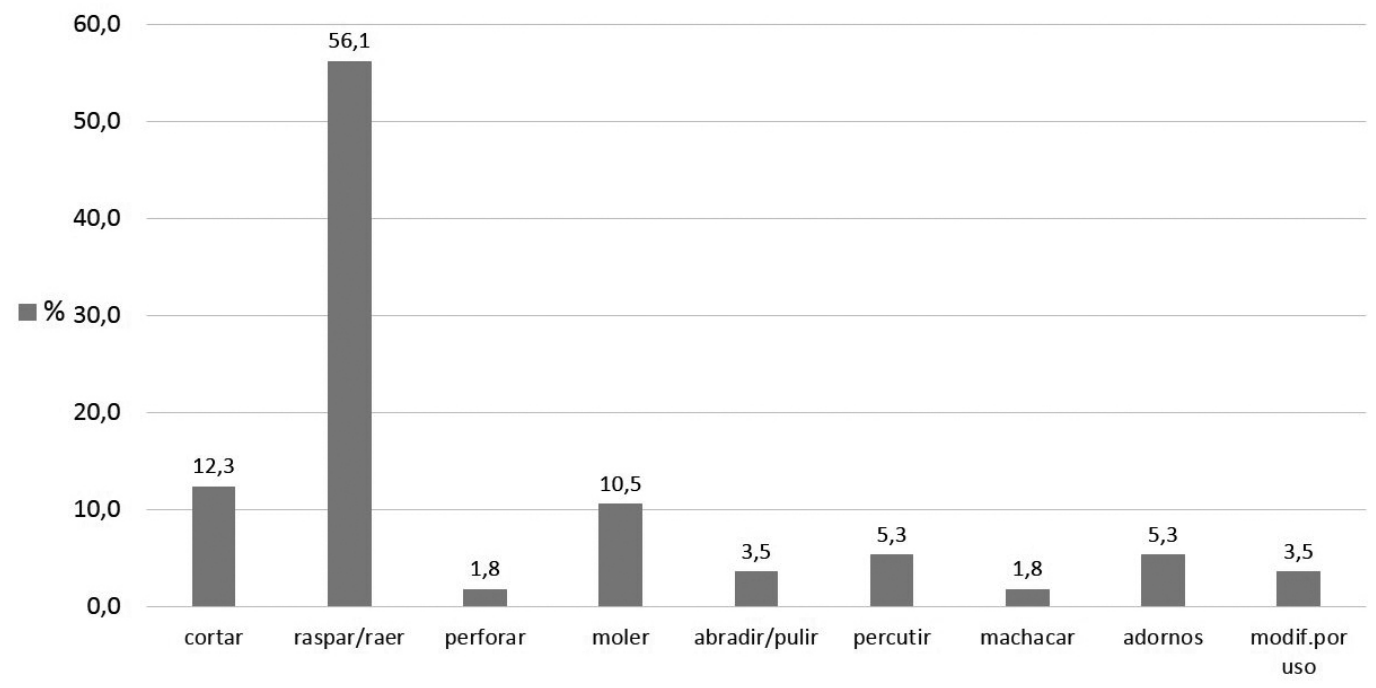

Figura 14. Porcentaje de instrumentos líticos y clasificación de funciones hipotéticas en el PA68.

Percentage of lithic instruments and classification of hypothetical functions in the PA68.

y reactivación sobre materias primas, en la que no predominan los instrumentos descartados, señalan la conservación y posiblemente el traslado de los mismos. Hay residuos de reactivación de filos, pero exclusivamente sobre materias primas silíceas no locales y de excelente calidad, lo que indicaría trayectorias conservadas de artefactos elaborados con tales materiales pero que no se descartaron en este sitio, sino que funcionaron y fueron mantenidos allí.
A la evidencia lítica, se agrega la presencia de dos cuentas de malaquita y un tembetá cilíndrico, objetos vinculados con el arreglo personal, que fueron recuperados en la superficie (Figura 15).

\section{Discusión}

El PA68 es el sitio de mayor tamaño detectado en los complejos de humedal dependientes del Río 


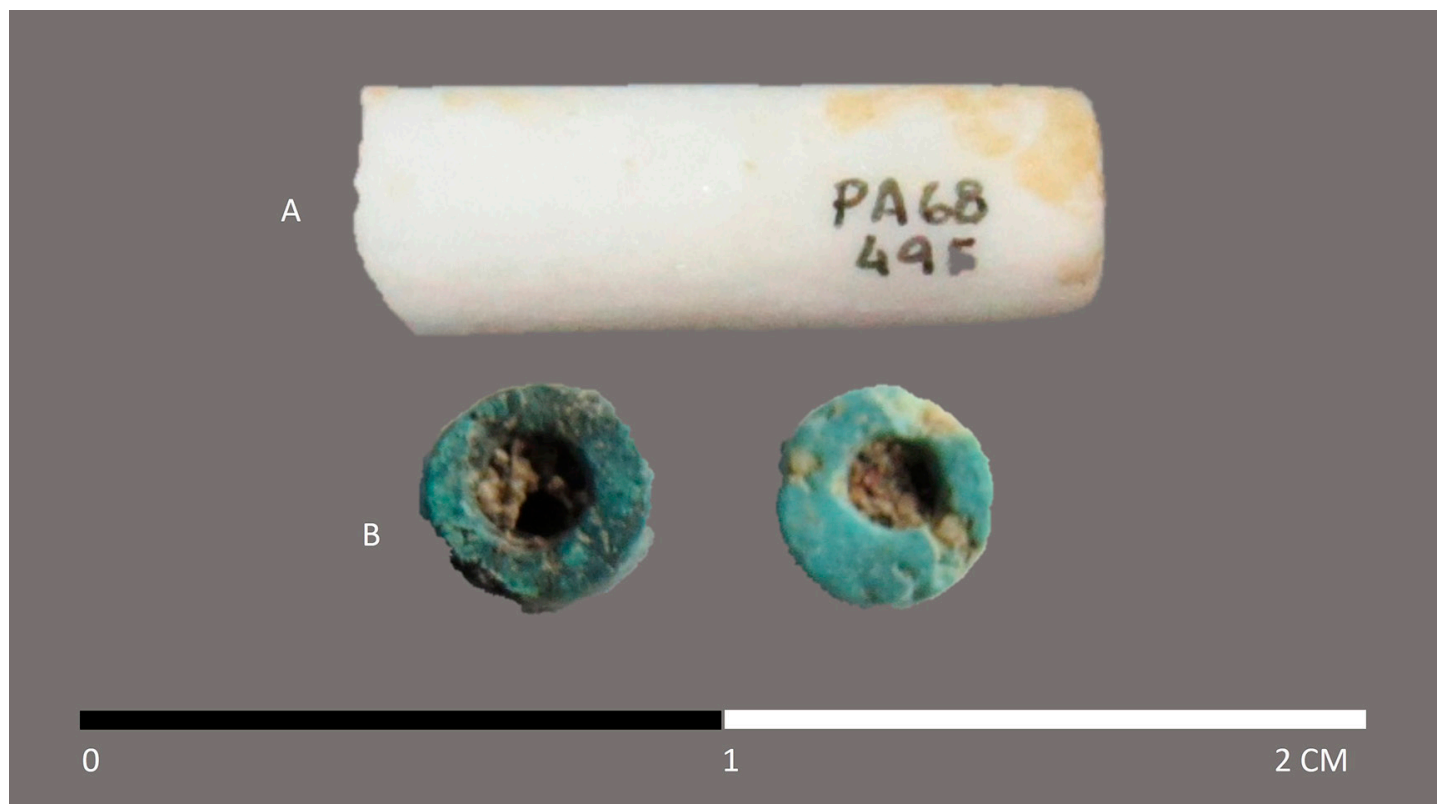

Figura 15. Ornamentos de material lítico del PA68. (A) Fragmento de tembetá de piedra; (B) cuentas de malaquita.

Lithic ornaments from PA68. (A) Fragment of stone tembetá; (B) malachite beads.

Desaguadero y relevados en las investigaciones que desarrollamos hace más de diez años. De acuerdo a los resultados de las dataciones y en relación con otros sitios de la región (Chiavazza 2014), posee niveles intermedios de resolución temporal, debido tanto a los procesos postdepositacionales como a las características de ocupación más estable, sea por mayor permanencia o recurrencia. El análisis de estacionalidad de los otolitos indica una transestacionalidad de uso para toda la secuencia del sitio. Esto permite, junto a los índices de diversidadhomogeneidad obtenidos, proponer el rol relevante que tuvo la pesca en el contexto económico a lo largo de la historia ocupacional, además de una localización específica de su procesamiento, ya que los restos de peces y los restos termoalterados se concentran en el PA68.1 (Tabla 3).

Por su parte, el conjunto lítico, posee un volumen que se destaca en el contexto regional (Chiavazza 2012a, 2012b, 2014). Entendemos que tal acumulación y el significativo índice de descarte, respondería a una estrategia de aprovisionamiento constante del sitio, haciendo previsible la disponibilidad de rocas, un recurso inexistente en las inmediaciones. La diversidad de tipos de materias primas explotadas es alta, fortaleciendo la idea de que el sitio concentró recursos de procedencias variadas y distantes. La consideración de cantidad de materias primas versus el peso de las mismas, indica un fuerte énfasis cuantitativo en el aprovechamiento y talla (secundaria) de las de mejor calidad (incluso con restos vinculados a la reactivación y mantenimiento) y por contraste, el acopio y trabajo sumario sobre materias primas de menor calidad (mayor peso). Las primeras, proceden de ambientes distantes y ubicados en otra unidad geográfica, la precordillera (MPR), en tanto que las menos economizadas son de la misma planicie (MPL). No obstante, los instrumentos descartados en el sitio son de materias primas predominantemente de Sierras Pampeanas (MPS), lo que contrasta con el predominio de restos de talla secundaria adscribibles a MPR. Las dificultades para la talla de las cuarcitas de MPS explicaría, en parte, su aplicación a instrumentos con baja estandarización. En cuanto a la relevancia de su uso, es una tendencia que se podría relacionar con los fragmentos de vasijas cerámicas halladas en el sitio y producidas con antiplásticos proveniente de Sierras Pampeanas (Prieto-Olavarría et al. 2016; PrietoOlavarría et al. 2019). Las actividades relacionadas con el instrumental, suponen el procesamiento (animal, vegetal y mineral, según filos, manos de moler y percutores) y la inexistencia de instrumentos relacionados con la extracción/obtención de recursos.

Las características generales del registro lo ubican en un lugar relevante dentro de la organización del sistema de asentamiento-subsistencia del área. 
Comparado con sitios de la Planicie NE en general y del Río Desaguadero en particular (Chiavazza 2014), su tamaño, densidad y diversidad de materiales, lo hacen un posible campamento base de uso trans-estacional o base residencial, ocupado intensivamente entre los años cal. 858-1150 AD y los años cal. 1159-1283 AD. Posteriormente, entre los años ca.1500 a $1600 \mathrm{AD}$, habría sido ocupado como campamento base y como parte del patrón de movilidad logística desarrollado por las poblaciones tardías. En este contexto, la variabilidad de estilos tecnológicos de la cerámica recuperada, se relacionaría con la presencia de conjuntos alfareros producidos por artesanos pertenecientes a tradiciones alfareras distintas, en un área definida como sector de borde en el eje este-oeste y como corredor en el eje norte-sur (Prieto-Olavarría et al. 2016).

Las ocupaciones se registraron sobre los cuerpos de dunas, donde los palimpsestos indicarían la acción eólica a lo largo del tiempo. Los procesos eólicos podrían relacionarse con el creciente aumento de temperatura y disminución de precipitaciones y humedad durante la PEH. Las ocupaciones más tempranas y coincidentes con la Anomalía Climática Medieval, responderían a la disponibilidad y previsibilidad de agua en un entorno en el cual es un recurso crítico y donde las particularidades del registro indican la existencia de condiciones de humedal, actualmente inexistentes. Los restos de arqueofauna reflejan una explotación orientada a la pesca, favorecida por las condiciones de humedal, y procesamiento intensivo en el sitio durante aproximadamente 400 años (entre ca. 850 y 1280 años AP), lo que es congruente con la idea de estabilidad ocupacional. Estos resultados, más la evidencia cerámica y las dataciones obtenidas, indican la intensidad de uso durante la Anomalía Climática Medieval. En el marco regional, el desarrollo de este sistema de subsistencia en la Planicie NE, se vincularía con procesos de sedentarización y los consecuentes cambios en la organización de la economía política y social (Chiavazza 2012b), lo cual se corresponde con el aumento demográfico registrado a partir de la proliferación regional de sitios datados (Gil et al. 2014) dentro del rango del PA68. Por su parte, la estrategia expeditiva en la tecnológica lítica, aunque con evidencias de prácticas curatoriales (sensu Nelson 1991), también indican estabilidad y persistencia de uso del sitio. En el marco del posible uso recurrente, la práctica de acopio de materias primas líticas habría permitido que las herramientas fueran elaboradas de modo congruente con la necesidad de uso e inmediatamente descartadas (Nelson 1991), lo que podría asociarse a ocupaciones más estables.

\section{Conclusiones}

Las características del registro dan cuenta de sociedades de baja escala, siendo el PA68 uno de los más grandes de la Planicie NE con evidencias de estabilidad e intensidad ocupacional. La orientación hacia la pesca detectada en el sitio, se habría desarrollado en el marco de las economías mixtas descritas para el norte y centro de Mendoza, las que, en los valles pedemontanos de Mendoza y Uco, y en el precordillerano de Potrerillos (Chiavazza 2015b; Gasco et al 2011; Ots et al. 2016), manifiestan rasgos de una conjugación entre extractivas (caza-recolección y pesca) y productivas (agrícolas). Hasta el siglo XVIII la documentación da cuenta de patrones de movilidad alta entre los pobladores de la zona, con construcciones efímeras y abandonos circunstanciales, dependientes de la disponibilidad de agua (Chiavazza 2014). A su vez, los asentamientos históricos no indicarían existencia de poblados, sino de puestos habitados por familias extensas. Esto contrastaría con la estabilidad detectada en el PA68, cuya ubicación en un sector de humedal durante la Anomalía Climática Medieval, sumado a la característica de borde en el eje este-oeste y de corredor en el norte-sur, podrían haber sido estímulos para la circulación y el asentamiento poblacional. Estos grupos, de acuerdo a las materias primas cerámicas y líticas, habrían estado vinculados tanto al norte de Mendoza como a las Sierras Pampeanas, ubicadas al este.

En resumen, la relación entre el uso de materias primas líticas de otras áreas, la variabilidad alfarera, la posición del sitio en un humedal dentro de un territorio árido extendido y las condiciones ambientales variables registradas en los últimos 2000 años, permitirían proponer que en el periodo comprendido entre los ca. 800 y $1200 \mathrm{AD}$, el sector concentró ocupaciones posiblemente en dos momentos. Estas habrían tenido cierto grado de estabilidad y se habrían centrado en la explotación de diversos recursos, aunque con énfasis en los obtenidos de la pesca. Estas poblaciones participaron de los patrones de movilidad regional, favorecidos posiblemente por las condiciones climático-ambientales de la Anomalía Climática Medieval. Por otra parte, entre los ca.1500 a $1600 \mathrm{AD}$, el sitio fue ocupado por grupos provenientes del oeste y portadores de cerámica Viluco Inca Mixto, los que realizaron ocupaciones discretas y posiblemente orientadas a actividades 
específicas como la pesca -documentada aún hasta la colonia temprana- lo que se produjo en un creciente proceso de aridización generado durante la PEH. En ese lapso, los procesos de conquista y consolidación de los estados Inca y español, operaron presionando a los grupos locales a moverse hacia sectores que comenzaron a ser ocupados de modo efectivo, como lo demuestra la documentación histórica (Chiavazza y Prieto 2015), vinculados a los procesos de incorporación de las poblaciones locales a modos de trabajo forzado como la encomienda.

Agradecimientos. Este proyecto fue financiado por la Secretaría de Ciencia Técnica y Posgrado
(SECTYP) de la Universidad Nacional de Cuyo, Proyecto Ocupación humana en el Monte Árido II (OHMA_II): estudios arqueológicos en el Río Desaguadero, Mendoza, Res. 4540/13-06/G653. También se contó con el apoyo del Centro de Investigaciones Ruinas de San Francisco (CIRSF), Área Fundacional, Municipalidad de Mendoza. Agradecemos por su colaboración en los trabajos de campo a Leonardo Castillo, Enzo Bontorno, Vanina Porta, Vanesa Guajardo, Sebastián Giannotti, Emiliano Araujo, Karina Castañar, Osvaldo Sironi, Luis Mafferra y Manuel López. Agradecemos los comentarios y sugerencias de los evaluadores que ayudaron a mejorar este trabajo.

\section{Referencias Citadas}

Abraham, E. y M.R. Prieto 1981. Enfoque diacrónico de los cambios ecológicos y de las adaptaciones humanas en el NE. Árido mendocino. Cuadernos del CEIFAR 8:109-139.

Aronson, S. 2008. Aridscapes. Proyectar en Tierras Ásperas y Frágiles. Editorial Gustavo Gili, Barcelona.

Aschero, C. 1983. Ensayo para una clasificación morfológica de artefactos líticos aplicada a estudios tipológicos comparativos. Apéndices A-C. Revisión. Cátedra de Ergología y Tecnología. Facultad de Filosofía y Letras, Universidad de Buenos Aires, Buenos Aires.

Banaag, J. 2006. La desertificación en cifras. En Desertificación El Correo de la Unesco, junio p. 13. UNESCO, UNCCD.

Bereciartua, P. 2009. Estudio Integral de la Cuenca del Río Desaguadero-Salado-Chadileuvú-Curacó. Tomo I. Facultad de Ingeniería, Universidad de Buenos Aires, Buenos Aires.

Berenguer, J. y G. Pimentel 2017. Introducción al estudio de los espacios internodales y su aporte a la historia, naturaleza y dinámica de las ocupaciones humanas en zonas áridas. Estudios Atacameños. Arqueología y Antropología Surandinas 56:3-11.

Bruniard, E.D. 1982. La diagonal árida argentina: un límite climático real. Revista Geográfica 95:5-20.

Cahiza, P. 2003a. Ictioarqueología de las Lagunas de Guanacache (Mendoza, Argentina). Identificación y estacionalidad de captura a partir del análisis de otolitos sagitales. Relaciones de la Sociedad Argentina de Antropología 28:167-183.

Cahiza, P. 2003b. Paleogeografía de las tierras bajas de Mendoza y San Juan: un acercamiento arqueológico a la ocupación del espacio de las comunidades agroalfareras (siglos VI-XVIII DC.). Actas de las XV Jornadas de Geografía Cuyana, pp. 1-14. Facultad de Filosofía y Letras. Universidad Nacional de Cuyo, Mendoza.

Canals Frau, S. 1944. El grupo huarpe-comechingón. Anales del Instituto de Etnografía Americana 5:9-47.

Chiavazza, H. 1995. Estudios Arqueológicos en el sitio "Rincón de Los Helados" ("RH"). Ocupación Multicomponente en Noreste de Pampa de Canota - Departamento de Las Heras, Provincia de
Mendoza, República Argentina. Tesis de Licenciatura, Facultad de Filosofía y Letras, Universidad Nacional de Cuyo, Mendoza.

Chiavazza, H. 2001. Las Antiguas Poblaciones de las Arenas. Arqueología en las Tierras Áridas del Noreste Mendocino. Serie Bienes Patrimoniales. Ediciones Culturales de Mendoza, Mendoza.

Chiavazza, H. 2007. Cambios Ambientales y Sistemas de Asentamiento en el Árido Normendocino. Arqueología en los Paleocauces del Río Mendoza. Tesis doctoral, Facultad de Ciencias Naturales y Museo, Universidad Nacional de La Plata, La Plata.

Chiavazza, H. 2009. Garganta seca y arena en las botas: prospectando antecedentes arqueológicos en las tierras áridas del noreste de Mendoza. Arqueología Iberoamericana 1 (1):41-71.

Chiavazza, H. 2012a. Ocupaciones humanas en la planicie árida Noreste de Mendoza: estudios arqueológicos en el Paleocauce Central (PC4). Relaciones de la Sociedad Argentina de Antropología 37 (2):299-327.

Chiavazza, H. 2012b. Adaptaciones humanas en contexto áridos: ambiente y patrón de asentamiento prehispánico en el NE de Mendoza. Actas del XVIII Congreso Nacional de Arqueología Chilena, pp. 381-391. Sociedad Chilena de Arqueología, Valparaíso.

Chiavazza, H. 2014. Tendencias regionales del registro arqueológico en sociedades sin estructura aldeana del Noreste de Mendoza. En Distribución Espacial en Sociedades no Aldeanas: del Registro Arqueológico a la Interpretación Social, editado por F. Falabella G., L. Sanhueza R., L. Cornejo B. e I. Correa, pp. 221-249. Serie Publicaciones Monográficas de la Sociedad Chilena de Arqueología 4. Universidad de Chile, Santiago.

Chiavazza, H. 2015a. Estudio de contextos recuperados en los paleocauces del monte árido, NE de Mendoza (Argentina). Anales de Arqueología y Etnología 70-71:137-158.

Chiavazza, H. 2015b. Pescadores y horticultores ceramistas del valle de Mendoza. Xama 5:45-62.

Chiavazza, H. y V. Cortegoso 2004. De la cordillera a la llanura. Disponibilidad regional de recursos líticos y organización de la tecnología en el norte de Mendoza. Chungara Revista de Antropología Chilena 36, Número especial 2, pp.:723-737. 
Chiavazza, H. y F. Hernández 2015. Pescadores del desierto. Ocupación humana y subsistencia en el noreste de Mendoza. Libro de resúmenes VI Jornadas Arqueológicas Cuyanas, pp. 23. CTDR Los Reyunos, San Rafael, Mendoza.

Chiavazza, H. y M.R. Prieto 2008. Estudios arqueológicos en el Río Desaguadero (Mendoza). Runa 29:29-51.

Chiavazza, H. y M.R. Prieto 2015. El río Desaguadero: corredor cultural en la historia de Cuyo. En Restauración de un Sistema Ecológico Compartido: Estudio Ambiental del Sitio Ramsar Guanacache, Desaguadero y Bebedero editado por R. Candia, H. Chiavazza, S.M. Devincenzi, J. Elizondo, M.B. Guevara, G. De los Santos Gómez, S. Moreiras, G. Pastor, M.R. Prieto, A.G. Rodríguez Salas, O.M. Saá, H. Sosa, L. Torres y E. Torres, pp. 115-139. Editorial Dunken, Buenos Aires.

Chiavazza, H., C. Prieto-Olavarría, F. Hernández, L. Castillo y M. Quiroga 2014. Ocupaciones humanas de humedales en desiertos: estudios arqueológicos en el río Desaguadero, Mendoza. Resúmenes II Jornadas Profesor Salvador Canals Frau, pp. 29-30. Instituto de Arqueología y Etnología, Facultad de Filosofía y Letras, Universidad Nacional de Cuyo, Mendoza.

Cioccale, M.A. 1999. Climatic fluctuations in the Central Region of Argentina in the last 1000 years. Quaternary International 62:35-47.

Corbat, M. 2015. Variabilidad Ambiental y Sociocultural en la Explotación de Peces en el Centro-Occidente Argentino: una Evaluación Zooarqueológica. Tesis doctoral inédita, Facultad de Filosofía y Letras, Universidad de Buenos Aires, Buenos Aires.

Cortegoso, V., G. Lucero y S. Castro y Diego Winocur 2017. Bosques fósiles y tecnología humana: la explotación de materias primas líticas en el Bosque de Darwin, Paramillos (Argentina). Latin American Antiquity 28 (3):1-20.

Espizúa, L. y P. Pitte 2009. The Little Ice Age glacier advance in the Central Andes $\left(35^{\circ} \mathrm{S}\right)$, Argentina. Palaeogeography, Palaeoclimatology, Palaeoecology 281:345-350.

Guardia, N. y F. Francalancia 2015. Interpretación del registro zooarqueológico astillado en sitios del Noreste de Mendoza. ArqueoGasta III - Actas del XIV Congreso de Estudiantes de Arqueología, pp. 69-72. Facultad de Filosofía y Humanidades, Universidad Nacional de Córdoba, Córdoba.

Garreaud, R., M. Vuille, R. Compagnucci y J. Marengo 2009. Present-day South American climate. Palaeogeography, Palaeoclimatology, Palaeoecology 281:180-195.

Gasco, A., E. Marsh, C. Frigolé, S. Castro, C. Privitera, R. Moyano y L. Yebra 2011. Actividades domésticas durante los siglos IIIVIII d.C. en el valle de Potrerillos (San Ignacio-Mendoza). Un acercamiento desde la osteometría y la tecnología cerámica y lítica. Revista del Museo de Antropología 4:145-160.

Gil, A.F., M. Giardina, G. Neme y A. Ugan 2014. Demografía humana e incorporación del cultígenos en el centro occidente argentino: explorando tendencias en las fechas radiocarbónicas. Revista Española de Antropología Americana 44 (2):523-553.

Heider, G., E.G. Jobbágy y A. Tripaldi 2019. Uso del espacio semiárido por poblaciones prehispánicas: el papel de los paisajes de dunas como eco-refugios en el Centro de Argentina. Boletín de la Sociedad Geológica Mexicana 71 (2):229-248.

Hijmans, R.J., S.E. Cameron, J.L. Parra, P.G. Jones y A. Jarvis 2005. Very high resolution interpolated climate surfaces for global land areas. International Journal of Climatology 25:1965-1978.
Higham, T.F. y P.L. Horn 2000. Seasonal dating using fish otoliths: Results from the Shag River Mouth site, New Zealand. Journal of Archaeological Science 27:439-448.

Lagiglia, H. 1978. La Cultura de Viluco del Centro Oeste Argentino. Revista del Museo de Historia Natural. III (1-4):227-265.

López, J.M. y H. Chiavazza 2019. Amidst wind, sand and raptors. Small mammal bone remains recovered in open-air archaeological sites from the Monte Desert in Central Western Argentina: Taphonomic and palaeoenvironmental implications. Archaeological and Anthropological Sciences 11:5149-5169.

Markgraf, V. 1989. Palaeoclimates in central and south America since 18,000 BP based on pollen and lake-level records. Quaternary Science Reviews 8:1-24.

Mengoni Goñalons, G.L. 2010. Zooarqueología en la práctica: algunos temas metodológicos. Xama 19-23:83-113.

Morello, J. 1959. La Provincia Fitogeográfica del Monte. Fundación Miguel Lillo, Tucumán.

Nelson, M. 1991. The study of technological organization. En Archaeological Method and Theory, editado por M.B. Schiffer, pp. 57-100. Academic Press, Nueva York.

Norte, F. 2000. Mapa climático de Mendoza. En Argentina. Recursos y Problemas Ambientales de la Zona Árida. Primera Parte. Provincias de Mendoza, San Juan y La Rioja, editado por E. Abraham y F. Rodríguez Martínez, Tomo 1. pp. 25. Junta de Gobierno de Andalucía, Universidades y Centros de Investigación de la Región Andina Argentina, Mendoza.

Ojeda, G., D. Gómez y J. Chiesa 2012. Dunas lunetas en el ambiente del río Desaguadero y su implicancia paleoambiental. Mendoza. Argentina. Acta Geológica Lilloana 24:123-128.

Ojeda, G., J. Chiesa y D. Gómez 2013. Los depósitos eólicos asociados a la planicie aluvial del río Desaguadero, provincia de Mendoza, Argentina. Latin American Journal of Sedimentology and Basin Analysis 20 (2):105-128.

Ots, M.J., J. García Llorca y P. Cahiza 2016. Recursos y estrategias de consumo en el centro de Mendoza entre los siglos X-XVI AD. Intersecciones en Antropología 17:375-387.

Polanski, J. 1954. Rasgos Geomorfológicos del Territorio de la Provincia de Mendoza. Ministerio Economía, Instituto Investigaciones económicas y tecnológicas. Cuadernos de Investigaciones y Estudios 4:4-10.

Porta, V. y E. Bontorno 2015. Análisis tecnotipológico cerámico y aproximaciones al Cálculo del Número Mínimo de Vasijas del PA68, río Desaguadero, Mendoza. ArqueoGasta III - Actas del XIV Congreso de Estudiantes de Arqueología, pp. 121-124. Facultad de Filosofía y Humanidades, Universidad Nacional de Córdoba, Córdoba.

Prieto-Olavarría, C., B. Castro de Machuca y S. Pontoriero 2019. Estudio petrográfico de la cerámica de pescadores/cazadores/ recolectores del Alfarero Medio del río Desaguadero (Norte de Mendoza). Libro de Resúmenes XX Congreso Nacional de Arqueología Argentina, pp. 1522-1523. Universidad Nacional de Córdoba, Córdoba.

Prieto-Olavarría, C., H. Chiavazza, L. Castillo, V. Tobar, E. Bontorno y V. Porta 2017. Estado actual de las investigaciones de la cerámica indígena del norte de Mendoza. Tecnología, cronología y distribución. Revista del Museo de Antropología 1:95-104. 
Prieto-Olavarría, C., H. Chiavazza, V. Porta y E. Bontorno 2016. Variabilidad alfarera y procesos ambientales en un sitio de límite cultural. Estilos tecnológicos de la cerámica del río Desaguadero (PA68) (Mendoza, Centro Oeste argentino). Relaciones de la Sociedad Argentina de Antropología 41 (1):131-150.

Quintana, C.A. 2008. Cálculo del número mínimo de individuos en huevos de ñandú. Intersecciones en Antropología 9:93-97.

Rodríguez, E.J. y M. Barton 1993. El Cuaternario de la llanura. En Geología y Recursos Naturales de Mendoza, Relatorio XII Congreso Geológico Argentino, editado por V. Ramos, Tomo I, pp. 173-194. Akian Gráfica Editora, Buenos Aires.

Roig, F.A., E. Martínez Carretero y E. Méndez 2000. Vegetación de la Provincia de Mendoza. En Argentina. Recursos y Problemas Ambientales de la Zona Árida. Primera Parte. Provincias de Mendoza, San Juan y La Rioja, editado por E. Abraham y F. Rodríguez Martínez, Tomo 1. pp. 59-62. Junta de Gobierno de Andalucía, Universidades y Centros de Investigación de la Región Andina Argentina, Mendoza.

Rusconi, C. 1962. Poblaciones Pre y Posthispánicas de Mendoza. Arqueología. Vol. II. Imprenta Oficial, Mendoza.
Stuiver, M., P. Reimer y R.W. Reimer 2005. CALIB 5.0. [WWW program and documentation].

Trabucco, A. y R.J. Zomer 2009. Global Aridity Index (Global-Aridity) and Global Potential Evapo-Transpiration (Global-PET) Geospatial Database. CGIAR Consortium for Spatial Information. http://www.csi.cgiar.org/, (15 octubre 2019).

Tripaldi, A. y S. Forman 2007. Geomorphology and chronology of Late Quaternary dune fields of Western Argentina. Palaeogeography, Palaeoclimatology, Palaeoecology 251:300-320.

Veth, P. 2005. Conclusion: Major themes and future research directions. En Desert Peoples. Archaeological Perspectives, editado por P. Veth, M. Smith y P. Hiscock, pp. 293-300. Blackwell Publishing Ltd., London.

Villalba, R. 1994. Tree-Rings and glacial evidence for the Medieval Warm Epoch and the Little Ice Age in Southern South America. Climatic Change 30:1-15.

Wheeler, A. y A. Jones 1989. Fishes. Cambridge University Press, Nueva York.

\section{Notas}

1 A partir del análisis de los 58 fechados propios, se organizaron por coincidencia estadística 10 componentes (C). La fecha más antigua de ocupación en ambiente del Monte (CI) remite a contextos de planicie y piedemonte con ca. 3300 años AP. Los componentes CVII y CVIII, suponen un $15 \%$ y $17 \%$ del total, siendo a su vez predominante las ocupaciones en tierras bajas. 2 Esto de acuerdo con el diseño de filos, ya que la confirmación requiere estudios funcionales. 